\title{
Stopping Power Measurements with the Time-of-Flight (ToF) Technique
}

\author{
Cristiano L. Fontana ${ }^{\mathrm{a}}$, Chien-Hung Chen ${ }^{\mathrm{b}}$, Miguel L. Crespillo ${ }^{\mathrm{b}}$, Joseph T. Graham ${ }^{\mathrm{b}}$, Haizhou Xue ${ }^{\mathrm{b}}$, Yanwen \\ Zhang, ${ }^{\mathrm{a}, \mathrm{b}}$, William J. Weber ${ }^{\mathrm{a}, \mathrm{b}}$ \\ ${ }^{a}$ Materials Science 83 Technology Division, Oak Ridge National Laboratory, Oak Ridge, TN 37831, USA \\ ${ }^{b}$ Department of Materials Science 85 Engineering, University of Tennessee, Knoxville, TN 37996, USA
}

\begin{abstract}
A review of measurements of the stopping power of ions in matter is presented along with new measurements of the stopping powers of $\mathrm{O}, \mathrm{Si}, \mathrm{Ti}$, and $\mathrm{Au}$ ions in self-supporting thin foils of $\mathrm{SiO}_{2}, \mathrm{Nb}_{2} \mathrm{O}_{5}$, and $\mathrm{Ta}_{2} \mathrm{O}_{5}$. A Time-of-Flight system at the Ion Beam Materials Laboratory at the University of Tennessee, Knoxville was used in transmission geometry in order to reduce experimental uncertainties. The resulting stopping powers show good precision and accuracy and corroborate previously quoted values in the literature. New stopping data are determined.
\end{abstract}

Keywords: Stopping Power, Time-of-Flight, Elastic Recoil Detection Analysis, Ion Beam Analysis, Energy Loss PACS: 34.50.Bw, 82.80.Rt, 07.05.Hd, 61.80.Jh

\section{Introduction}

The measurement of the energy loss of ions in materials is of crucial importance in a number of academic and industrial fields [1-5]. For example, an accurate knowledge of the stopping power is essential for compositional and structural analysis of thin films and surfaces utilizing Ion Beam Analysis (IBA) techniques, [6-9] in computational and experimental studies of radiation effects and radiation damage in materials and electronics under extreme conditions, [10] in electronic device fabrication, [11] nuclear physics, [12] astrophysics, [13] and medical physics, [14]. Despite the fundamental importance of measured stopping power data to these fields, there are still numerical disagreements between energy loss models and measured values for various combinations of ion and target $[15,16]$.

\section{Methods}

There are two main classes of methods for measuring stopping powers. The first class relies on back-scattering ions from materials $[7,17-20]$; while in the second case, ions are transmitted through a thin foil [21-24]. Backscattering methods are ideally suited to measure the stopping powers of light ions in heavy materials (materials with high- $Z$ elements). In addition of being able to measure stopping powers in random incident ion directions, this technique has also been adapted to measurements along ion channeling directions $[18,20]$. On the other hand, the transmission method is the more versatile of the two because it can be used both for light and heavy ions in

Email address: fontana@pd.infn.it (Cristiano L. Fontana) light or heavy matrices. However, the need for uniform, free-standing thin films and the potential for film contamination pose additional challenges [25]. It has been shown that the two approaches can be complementary [25].

\subsection{Back-Scattering Techniques}

Backscattering techniques rely on measuring the energies of ions directly backscattered off the target material. If the sample composition, density, and layer structure is known, the stopping power can be inferred from the energy spectrum of the backscattered particles. Accuracy better than $2 \%$ error has been achieved with monochromatic He ions in the $\mathrm{MeV}$ range on a silicon target [18]. In this study, the thickness $(\sim 1 \mu \mathrm{g})$ of the sample was determined by Near-InfraRed (NIR) spectrometry. Similar accuracies were obtained for several $\mathrm{MeV} \mathrm{C}, \mathrm{O}$, and $\mathrm{Cl}$ ions in $\mathrm{Si}$ and $\mathrm{Ta}_{2} \mathrm{O}_{5}$ targets by carefully fitting a model to the Rutherford Back-Scattering (RBS) spectra [7, 19]. Stopping powers of $\mathrm{He}$ and $\mathrm{Li}$ were both measured in the 0.1 to $10 \mathrm{MeV}$ range in $\mathrm{Si}$, and the sample structure was characterized by Transmission Electron Microscopy (TEM) and Atomic Force Microscopy (AFM) [20]. The TEM was employed to measure the sample thickness, and the AFM to measure the surface roughness.

\subsection{Transmission Techniques}

Transmission techniques rely on the measurement of an ion energy loss through a stopping foil. An ion beam is transmitted through a stopping foil, and its energy is measured before and after the foil. The foil is thin enough to keep the fractional energy loss small. Consequently, the precision of transmission techniques depends largely on the resolution and linearity of the energy measurement. Typically, the beam currents are small, thus sputtering is 
negligible [23]. In early experiments, an attenuated beam was transmitted through an insertable sample and its energy spectrum was measured by means of a silicon detector $[12,22]$. The energy loss was determined by comparing the spectra with and without the foil between the ion source and the detector. Measurements of the stopping powers over a range of energies were obtained by changing the energy of the ion beam in discrete intervals, and using Time-of-Flight ( $\mathrm{ToF}$ ) techniques to accurately measure the energy spectra. The thicknesses of the samples were also determined by an ion transmission technique. Energy loss measurements, similar to the stopping power measurements themselves, were performed using alpha particles emitted by ${ }^{241} \mathrm{Am}$ and ${ }^{212} \mathrm{Bi}$ sources. The stopping powers were given as ratios of the alpha particle energy loss.

A faster and more comprehensive approach uses a beam with a continuous energy spectrum, rather than a series of monochromatic beams. By scattering the main beam off a scattering target and orienting the detector at an angle away from the beam line, ions travelling toward the detector are scattered into a broad range of energies. The beam scatterer can be: a bulk sample containing light atoms, which are emitted as recoiled ions when hit with a grazing beam $[26,27]$, or a bulk sample containing heavy atoms (like $\mathrm{Au}$ ) that scatters the main beam [21, 28-31].

Energy measurements can be performed using conventional silicon detectors (having $4-5 \%$ uncertainties) $[12,22]$, or by combining ToF and silicon detector systems $(<3 \%$ uncertainties) $[21,28,29]$. The former has the advantage of simplicity in that it comprises only one detector. However, the incident ion beam must be monochromatic. The ToF \& Si detection system is more complex, but it permits the use of a continuous energy ion source [32]. There are also examples of energy measurements by ToF with bunched beams, in which the main beam is pulsed and the time of flight is measured from the pulse start. Uncertainties of $7 \%$ [33] and 2.5\% [34,35] have been achieved with this approach.

In recent years, stopping power instrumentation has mainly converged on the combination of ToF \& Si detectors (Fig. 1) [6, 36-39]. This design it is more versatile because: (1) as mentioned above, a continuous set of energies can be used, (2) multiple recoil ions can be measured simultaneously, and (3) ToF systems have good energy resolutions $(<3 \%$ error). An exception to this trend is found in reference [40], in which the energy is solely measured by a ToF detector and the incoming beam is monochromatic. This approach has the advantage of reducing the energy uncertainty because the propagated uncertainty from the incident ion energy is greatly reduced while the energy resolution is still good.

\section{ToF-Energy Systems}

A more detailed discussion of ToF systems is provided here. They usually comprise two detectors for the ToF measurement, and a third for the energy measurement.

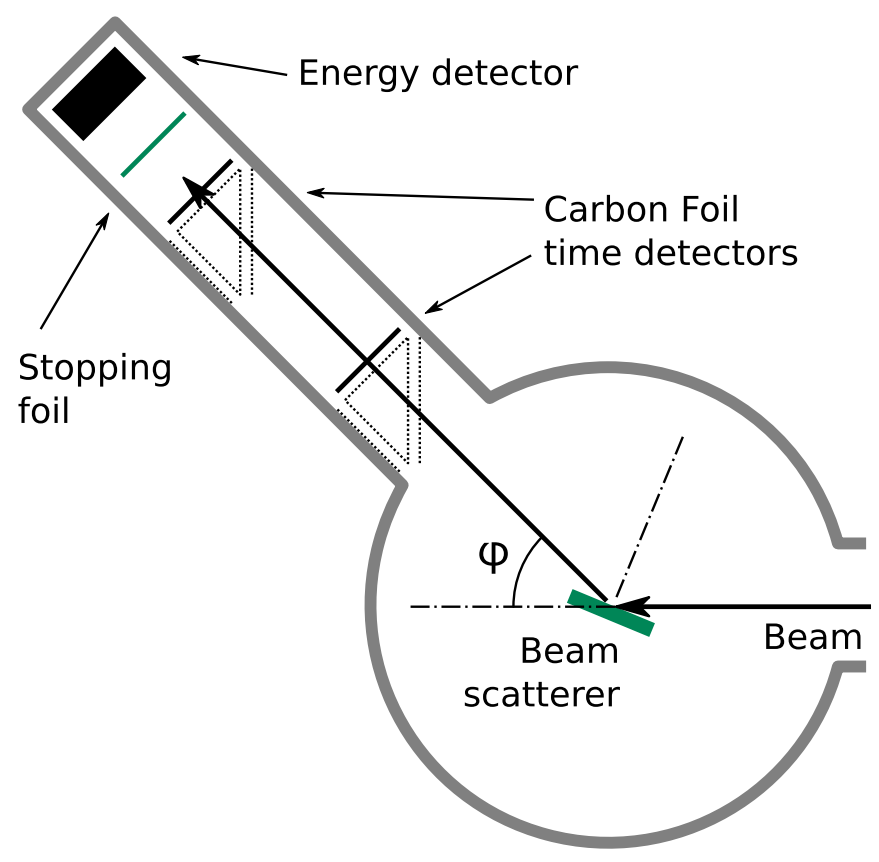

Figure 1: Typical experimental system for stopping power measurements. Two carbon foil time detectors are used to measure the Timeof-Flight ( ToF) of the ions, and a silicon energy detector is used to measure the total energy after the stopping foil.

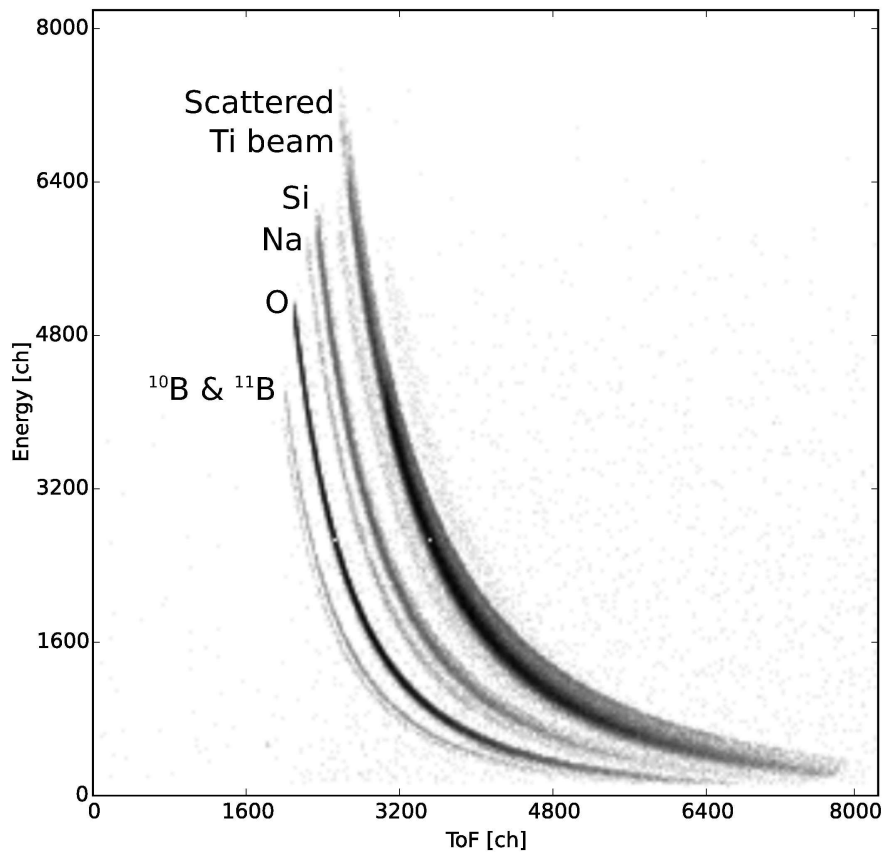

Figure 2: Recoils from an $18 \mathrm{MeV}$ Ti beam on a glass slide. The color scale is logarithmic. The mass lines from top to bottom correspond to: the forward scattered titanium beam, silicon, sodium, oxygen and the two isotopes of boron $\left({ }^{10} \mathrm{~B}\right.$ and $\left.{ }^{11} \mathrm{~B}\right)$. 
Although silicon detectors have been used for timing measurements (with $\sim 1$ ns resolution) [41, 42], Micro-Channel Plates (MCPs) with carbon foils are the typical choice for timing detectors $[4,43-45]$, because they have better timing resolutions (hundreds of picoseconds) [46, 47]. Other designs involve bunched beams and scintillators, which give resolutions of the order of $1 \mathrm{~ns}$. This type of design, however, requires a master clock to measure the pulse start [33-35].

Measurements are taken in coincidence mode with the three detectors. The information obtained for each ion is $t$, the ToF, and $E$, the total energy of the ion. The ToF is measured by the time difference of the signals arriving from the two timing detectors. The energy comes from the signal on the energy detector. The relationship between the two quantities is given by the classical kinetic energy formula

$$
E=\frac{1}{2} m\left(\frac{l}{t}\right)^{2}
$$

where $m$ is the mass of the ion and $l$ is the distance between the two time detectors. Different ions lie on different mass lines and thus they can be distinguished (Fig. 2 ). The energy signal can be thought of as a parameter for distinguishing between mass lines.

\subsection{ToF Detectors}

As mentioned earlier, the most common timing detectors are MCPs, due to their good timing resolution ( $\sim 100 \mathrm{ps})$. These detectors employ a thin carbon foil $\left(\sim 10 \mu \mathrm{g} / \mathrm{cm}^{2}[45]\right)$ that the ions pass through. As an ion passes through the carbon, it creates secondary electrons, some of which are detected by the MCP. Several geometries of carbon foil and MCP have evolved over the years (Fig. 3) to optimize both timing resolution and efficient transport of electrons to the detector. These designs include: (a) an isochronous transport detector that uses a magnetic field to deflect forward scattered secondary electrons through $180^{\circ}$ in a U-shaped path into the MCP $[48,49]$, (b) an isochronous transport detector in which the electrons are deflected into an MCP perpendicular to the carbon foil via an electrostatic mirror $[29,50]$, (c) an isochronous transport detector in which secondary electrons drift towards a biased annular detector [29, 51], and (d) a direct transport detector where the foil is not perpendicular to the beam and where the electrons drift to the MCP in a straight path. [52]. The isochronous electrostatic mirror approach (b) is the most common $[1,4,43,45,53,54]$, but the annular detector system has also been employed $[44,55]$. The annular geometry of the detector in method (c) avoids the need for accelerating electrostatic grids or magnetic deflectors [29, 51]. Grids attenuate the ion beam by absorbing a portion of the ions. This also generates false starts when ions pass though the foil but stop in the grid. The tilted carbon foil in method (d), while simple, results in a larger effective foil thickness. (a)

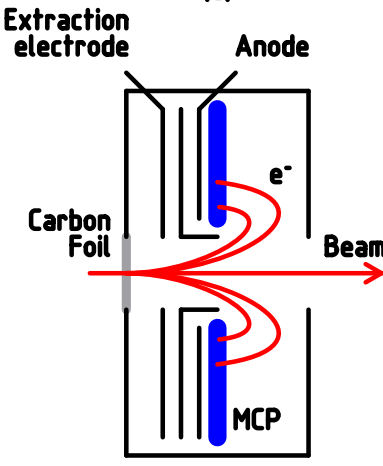

(c)

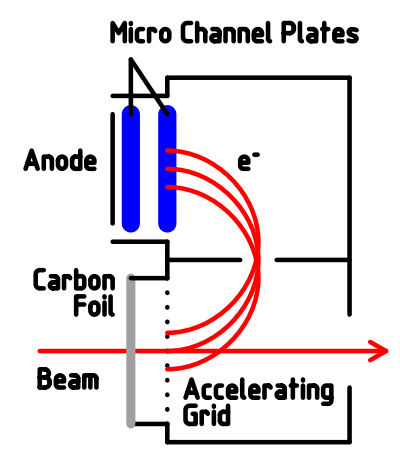

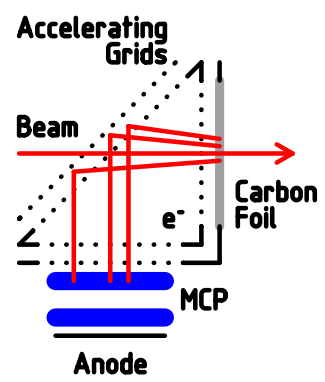

(b)

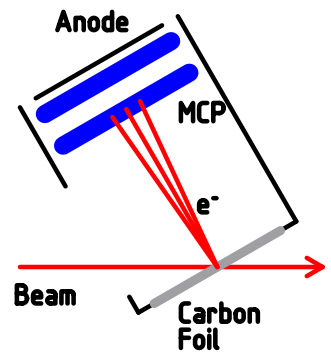

(d)
Figure 3: Schematic representations of the electron transport in different carbon foil time detector designs: (a) magnetic field deflector, (b) electrostatic mirror, (c) annular electrostatic mirror, (d) direct transport.

There are also examples of hybrid configurations [56, 57]. A drawback of carbon foil time detectors is their low detection efficiency for light elements. For example, it can be as low as $10 \%$ for hydrogen $[58,59]$.

In order to acquire ToF signals with a low dead-time, a start-stop inversion is normally used $[4,45,51,60]$. The first signal is delayed enough to arrive after the second signal. The first time detector, being closer to the sample, has a larger solid angle than the second time detector. Therefore, many of the ions passing through the first detector follow trajectories that miss the second detector. By using the second detector to trigger the timing measurement, more of the ions are collimated, thereby reducing the dead-time.

\subsection{Energy Detectors}

The ions energies can be measured using solid state detectors $[4,43,45,53,54]$ or Gas Ionization Chambers (GIC) $[53,61]$. Although only the ToF spectra are used in most analyses, the energy and the mass resolution are determined by both the ToF and energy detectors. Si detectors have limited mass resolution for recoils under the $\mathrm{MeV}$ range [53], but have a simple operation. The resolution in the low $\mathrm{MeV}$ range can be improved by using GIC detectors [53]. Moreover, Si detectors suffer from radiation damage accumulation. This problem is exacerbated if the system is used mostly for detecting heavy recoils. 
GIC performance is determined by the thickness and uniformity of the entrance window, as well as the stopping power and energy straggling of the ions in the window. Both Si detectors and GICs have nearly $100 \%$ efficiencies $[53,58]$.

\subsection{Thickness Determination}

The measured energy loss through a thin stopping foil does not provide enough information to determine the stopping power; the foil thickness has to be known as well. Foil thickness is an important source of uncertainty in the measurement $[62,63]$. Reasons for this are: many foils are non-uniform in thickness and/or composition, surface oxidation may be present, and thin foils may be difficult to measure with high accuracy. Several techniques appearing in the literature have been used to measure and verify the foil thickness. These include: measuring the energy loss of alpha particles from alpha emitters (i.e. ${ }^{241} \mathrm{Am}$ and ${ }^{212} \mathrm{Bi}$ ) and converting to thickness from tabulated energy loss values [12], measuring the energy loss of an alpha beam $[10,11,36,37,40,64-67]$, measuring the energy loss of a Li beam [26] and determining the thickness using tabulated stopping power values [68], direct measurement of the film thickness from cross sectional micrographs using TEM with surface roughness evaluated by Scanning Electron Microscopy (SEM) [11, 69-71], weight and area measurements [26, 30, 56, 72], by Rutherford Backscattering Spectrometry (RBS) on films grown on bulk substrates $[62,65,70,73]$, and by NIR spectrometry by comparing simulated and measured reflection spectra [18]. AFM $[6,67,73]$, and profilometry [62], have been used to determine the surface roughness and its contribution to the uncertainty.

\section{Data Analysis}

\subsection{Stopping Power Determination}

Some researchers have used ToF detectors to measure the initial ion energy and an energy detector to measure the final energy $[4,27,66,72]$. Others use the energy detector only to tag the energies $[26,37,38,56,63,65,74]$. In other words, a reference energy $\left(E_{\text {ref }}\right)$ is taken from the energy detector (Fig. 4) along with two values of the ToF corresponding to that energy. The first $\left(E_{\text {foil }}\right)$ is with the stopping foil in front of the detector, and the second, $E_{0}$, is without the foil (Fig. 1). The ToF measurements also determine the energy calibration of the energy detector. The reason for adopting this approach is to reduce errors due to non-linearities of the Si detector and its pulse height defect $[64,75,76]$.

The difference between the measured ion energies with and without the foil gives the energy loss.

$$
\Delta E=E_{\text {foil }}-E_{0}
$$

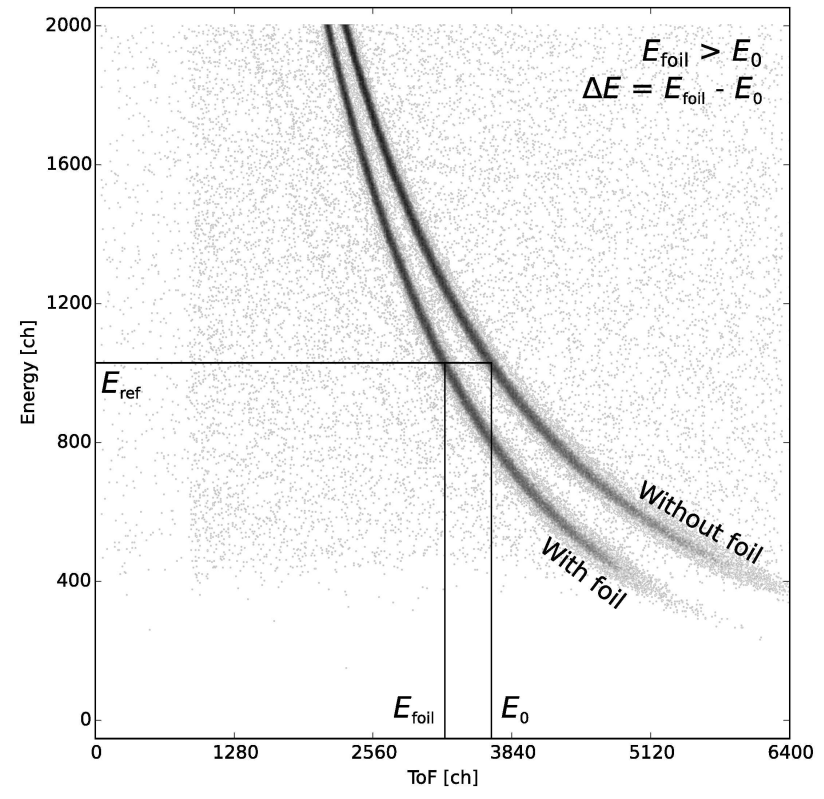

Figure 4: ToF-E spectra of He through $\mathrm{Ta}_{2} \mathrm{O}_{5}$. The energy detector is used as a reference for the energy loss measurement $(\Delta E)$. The energies are calculated from the ToF data, and the difference is taken between the energies with and without the stopping foil that give a pulse of the same height on the energy detector.

Then the stopping power can be determined by dividing the measured energy loss, $\Delta E$, by the foil thickness, $T$.

$$
S(\bar{E})=\frac{E_{\text {foil }}-E_{0}}{T} .
$$

When the stopping power is approximately constant in the foil (for a given ion and energy), the energy to which that stopping power value corresponds is the average between the initial and final energies [23, 30]

$$
\bar{E}=\frac{E_{\text {foil }}+E_{0}}{2} \text {. }
$$

This method breaks down for thick foils. Some authors propose to correct the measurement by assuming a functional shape for the stopping power inside the foil and fitting that to the data $[23,30]$.

\subsection{ToF Calibration}

One calibration method for ToF systems employs a multi-elemental sample that is irradiated with a heavy ion beam to generate recoils spanning a range of masses and energies. When a monochromatic beam is used to probe the elemental depth profiles of the scattering target, this method is called Elastic Recoil Detection Analysis (ERDA) [44]. Each recoiled element or isotope in the scattering target lies on a different mass line (Sec. 3). The high energy edge corresponds to the maximum energy, $T$, transferred from the incident ion to the recoil:

$$
T=\frac{4 m M E}{(M+m)^{2}} \cos ^{2} \varphi-\Delta E_{\text {carbon }}
$$




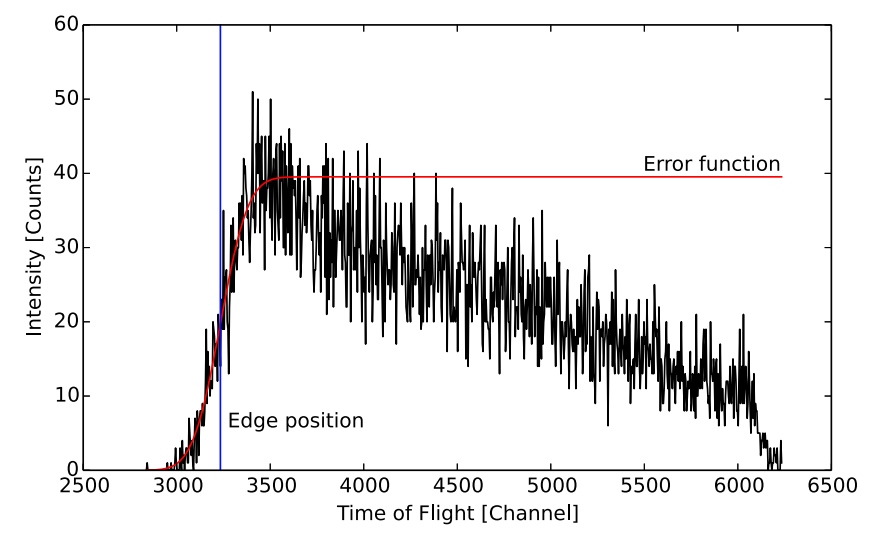

Figure 5: ToF spectrum of Au. The left edge, corresponding to the shortest flight time, was fitted with an error function to determine the maximum energy.

where $m$ is the mass of the recoil, $M$ the mass of the projectiles, $\varphi$ is the scattering angle, $E$ is the maximum beam energy and $\Delta E_{\text {carbon }}$ is a correction factor due to the energy loss on the first carbon foil. The edge of the distribution can be obtained by fitting it with an error function (Fig. 5) $[44,56]$. The calibration slope can also be determined employing a Time Calibrator module (e.g. ORTEC Model 462). Such slope value should be the same as the one obtained with the multi-elemental calibration.

\subsection{Energy Calibration}

After the timing is calibrated for the ToF system, the energy detector is calibrated from ToF measurements of recoiled ions. For each channel of the energy detector, there is a distribution of ToF values for each mass peak. By calculating some measure of the distribution's center, a calibration line can be defined. For silicon detectors, the distribution of light ions is typically symmetric (Fig. 6), but for heavy ions it becomes asymmetric (Fig. 7) [77]. In reference [77], the authors hypothesized that the high energy tails in the heavy ion distributions are a consequence of the channeling effect in the silicon detector. Moreover in [76], it is stated that the channeling can affect the pulse height even when the particle is fully stopped within the active volume, since nuclear collisions are less probable for channeled particles and therefore the PHD for heavy ions may be reduced. Channeling is possible because the ions are well collimated by the ToF arm. The channeling effect is more pronounced for heavier ions [1], therefore the asymmetry increases with ion mass. This hypothesis is corroborated by the observation that the asymmetry is removed when a stopping foil is inserted (Fig. 8). Presumably, the narrow angular distribution of the well collimated ion broadens into a wider distribution as scattering occurs within the foil. In the case of channeling, the high energy tail is attributed from pulse height defect and nonlinear response of Si detectors.

An earlier study [75] has shown that high rate recombination is not observed for heavy ions, in the region where

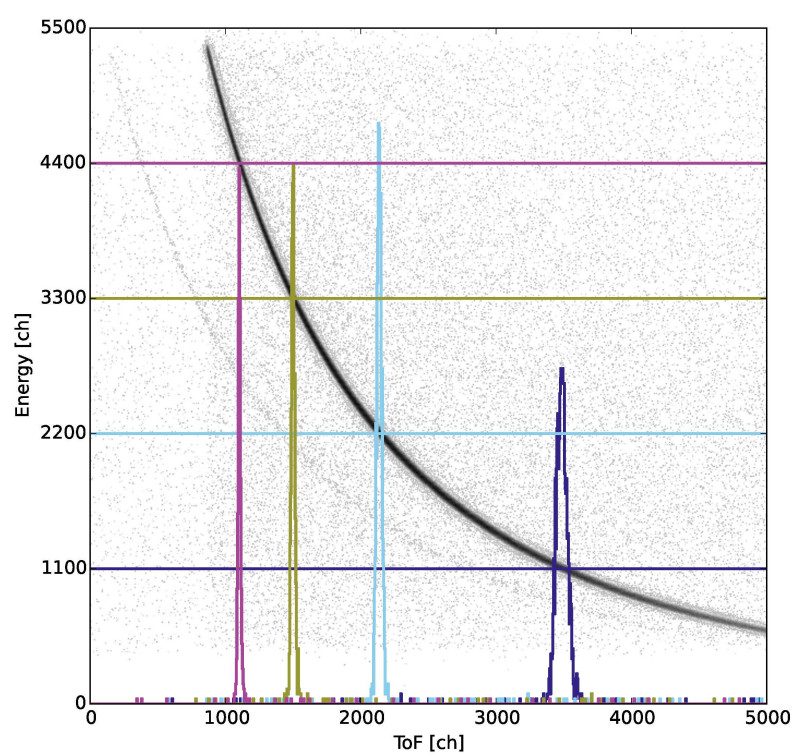

Figure 6: Examples of ToF spectra for selected energy channels, for a He beam. The color scale is logarithmic and the horizontal lines indicate the selected channel.

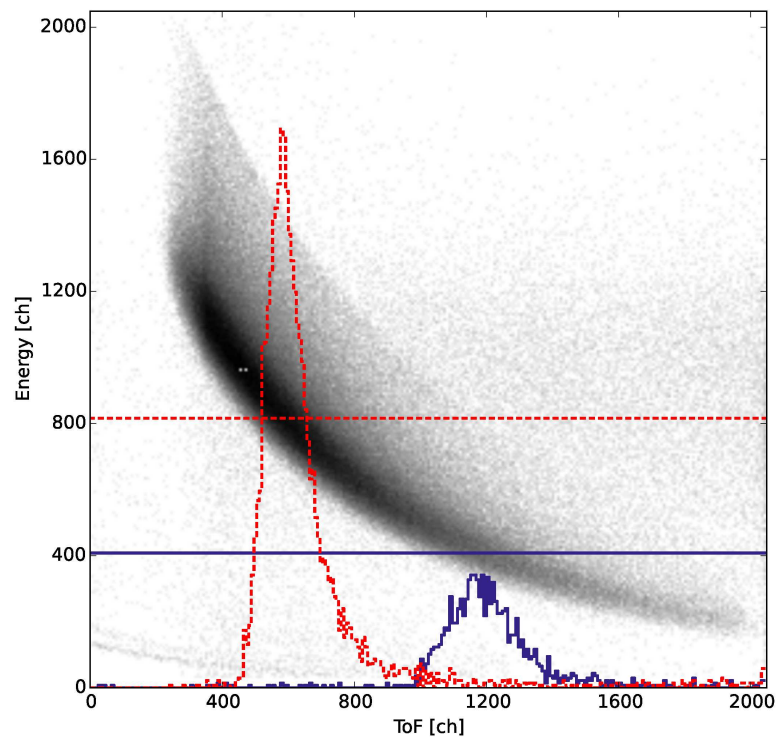

Figure 7: Examples of ToF spectra for selected energy channels, for a Au beam without a stopping foil. The color scale is logarithmic and the horizontal lines indicate the selected channel. 


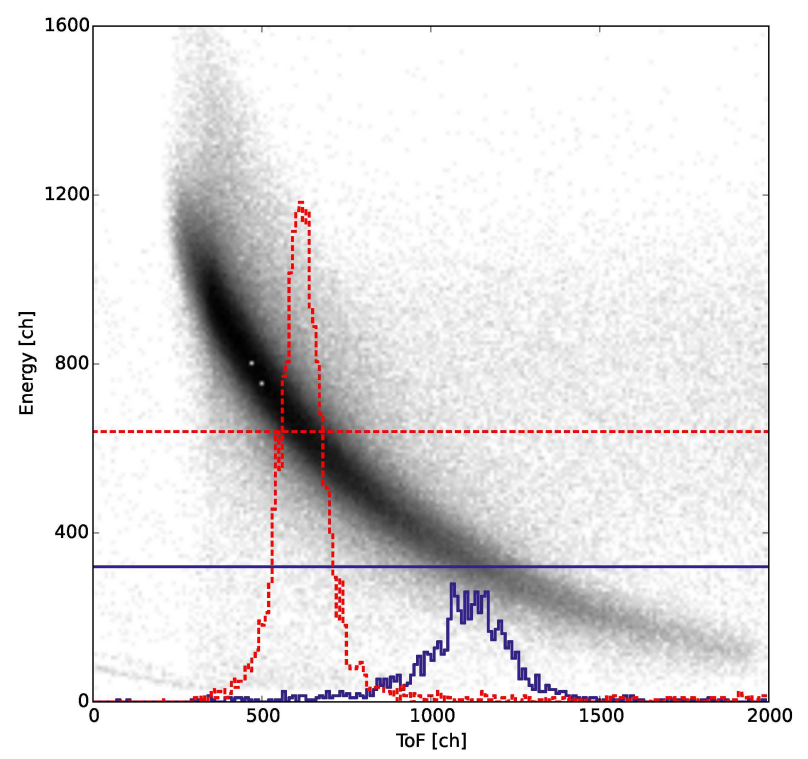

Figure 8: Examples of ToF spectra for selected energy channels, for a Au beam passing through a $\mathrm{Ta}_{2} \mathrm{O}_{5}$ foil $(369 \mathrm{~nm})$. The color scale is logarithmic and the horizontal lines indicate the selected channel.

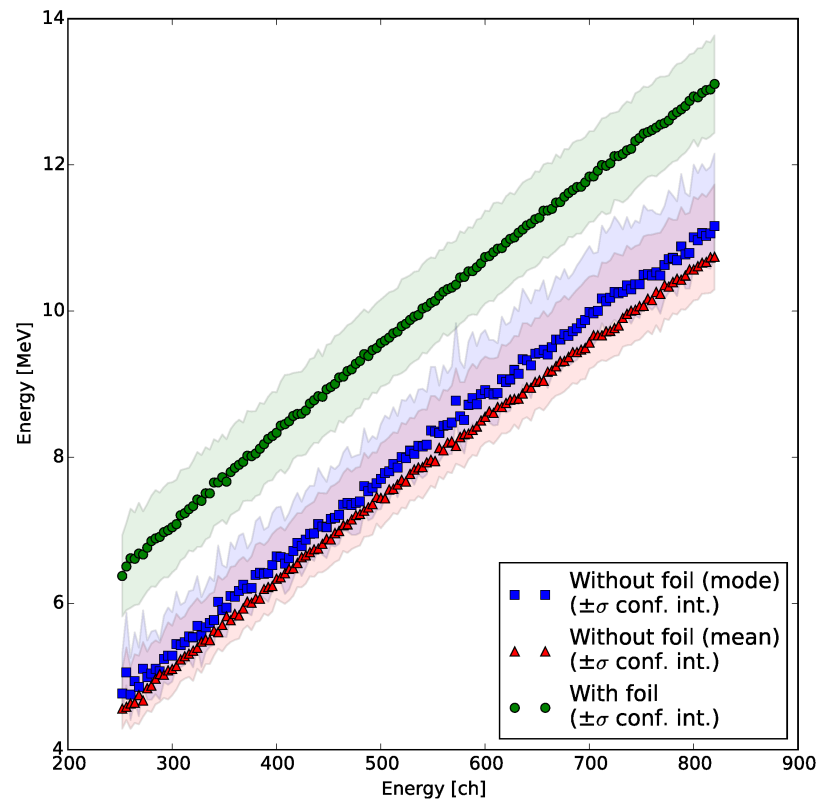

Figure 9: Measured energies of $\mathrm{Au}$ ions in a $\mathrm{Si}$ detector, calibrated with a $\mathrm{ToF}$ detector, with and without a $\mathrm{Ta}_{2} \mathrm{O}_{5}$ foil $(369 \mathrm{~nm})$ inserted in the beam.

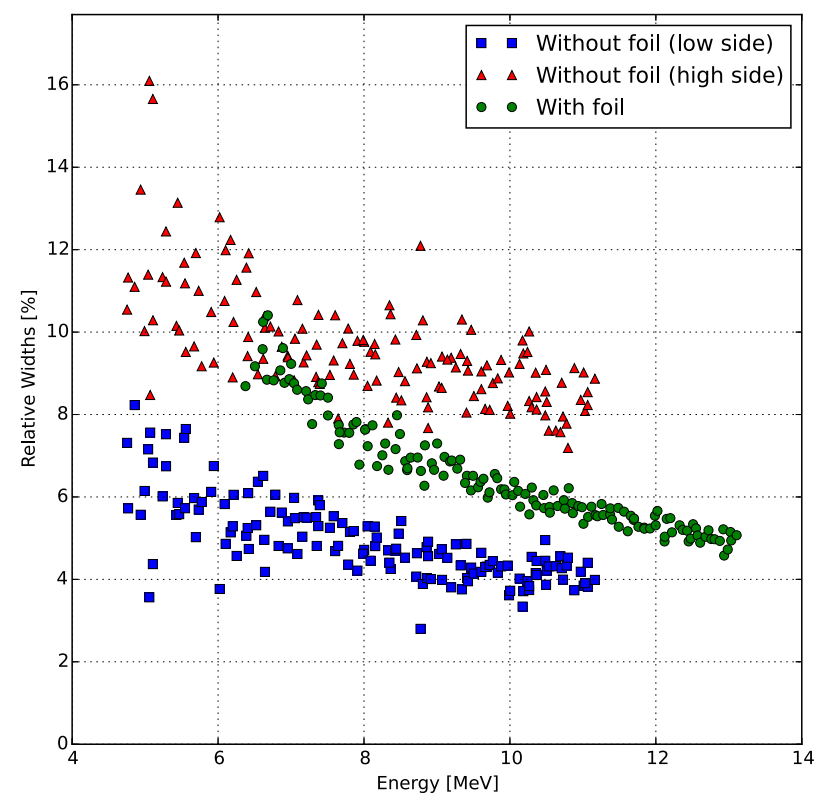

Figure 10: Widths of the energy distribution for $\mathrm{Au}$ ions with and without a $\mathrm{Ta}_{2} \mathrm{O}_{5}$ foil $(369 \mathrm{~nm})$ inserted in the beam.

higher density plasma is expected. On the other hand, significant trapping is explicitly observed with increasing atomic defects created by heavy ions through nuclear energy deposition, that leads to both nonlinear response at low energies and pulse height defect at high energies. A study [78] has also shown that collection of the electronhole pairs can be affected by thickness of entrance window of the detector, the energy deposited in non-ionizing processes within the active layer, and nonlinearity in the preamplifier response. Defect trapping and detector configuration, therefore, play important roles to the nonlinear response at both low and high energies. Non-channeled ions contribute to the lower energy, symmetric peak that is superimposed over the higher energy, asymmetric distribution from channeled ions. A binormal distribution can be fit to the data [79], thereby obtaining statistics such as the mode, the mean (Fig. 9) and the width (Fig. 10). The low energy tail has a narrower width with the foil removed (Fig. 10), confirming the effect of the straggling in the foil. The high energy tail, however, is wider. This can also be explained by the channeling effect in the detector. If channeling is the cause of this effect, then the mode of the distribution seems to be more meaningful; since one should compare the energy loss only using the non-channeled ions (assuming all ions after the stopping foil are non-channeled ions). The mean overestimates the ion energy when the pulse height defect correction is made. On the other hand, in [77] the mean was used as an estimate of the ion energy. 


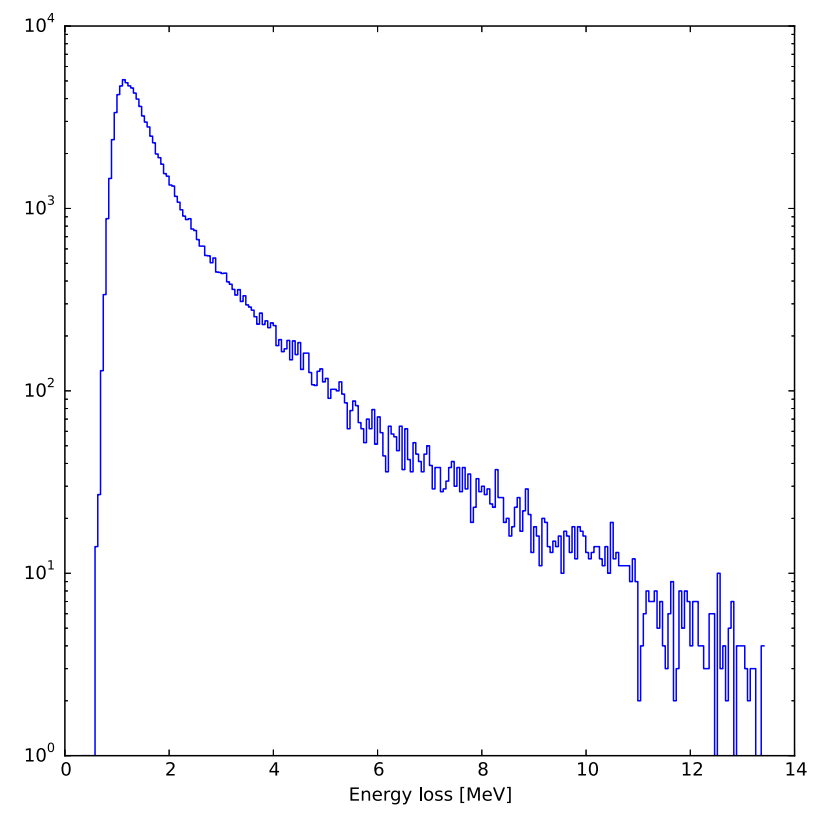

Figure 11: Energy loss distribution of $15 \mathrm{MeV} \mathrm{Au}$ in a $\mathrm{Ta}_{2} \mathrm{O}_{5}$ foil (369 nm).

\subsection{Range of Energies}

The energy range that can be probed is determined by the foil thickness. If the foil is too thin, it is difficult to measure energy loss above noise and uncertainty. If the foil is too thick, higher order effects such as multiple scattering should be taken into account. Reference [30] suggests using the range

$$
2 \lesssim \frac{E}{\Delta E} \lesssim 2000
$$

To increase the range, foils of two different thicknesses may be used. In the work presented here, stopping powers were measure for the following combinations of ion and energy range: $800 \mathrm{keV} / \mathrm{n}$ to $4 \mathrm{MeV} / \mathrm{n} \mathrm{O}, 800 \mathrm{keV} / \mathrm{n}$ to $3.5 \mathrm{MeV} / \mathrm{n}$ $\mathrm{Si}, 800 \mathrm{keV} / \mathrm{n}$ to $3 \mathrm{MeV} / \mathrm{n} \mathrm{Ti}$, and $300 \mathrm{keV} / \mathrm{n}$ to $700 \mathrm{keV} / \mathrm{n}$ $\mathrm{Au}$, in foils between $300 \mathrm{~nm}$ and $400 \mathrm{~nm}$ thick.

\subsection{Nuclear Stopping Power Correction}

If the nuclear stopping power is negligible, the energy loss is governed by the electronic stopping power, which does not sensitively depend on the scattering angle (neglecting the channeling directions). Depending on the combination of the ion, sample material, and energy range, the nuclear and electronic stopping powers can be comparable, in which case, it is necessary to calculate the nuclear contribution and its angular dependence [77, 80]. TRIM predictions are generally accurate enough for this purpose $[77,80]$.

For the experimental data presented in this manuscript, several TRIM [15] simulations of the aforementioned ion, target and energy combinations were performed. The energy loss distribution at each angle is asymmetric due to

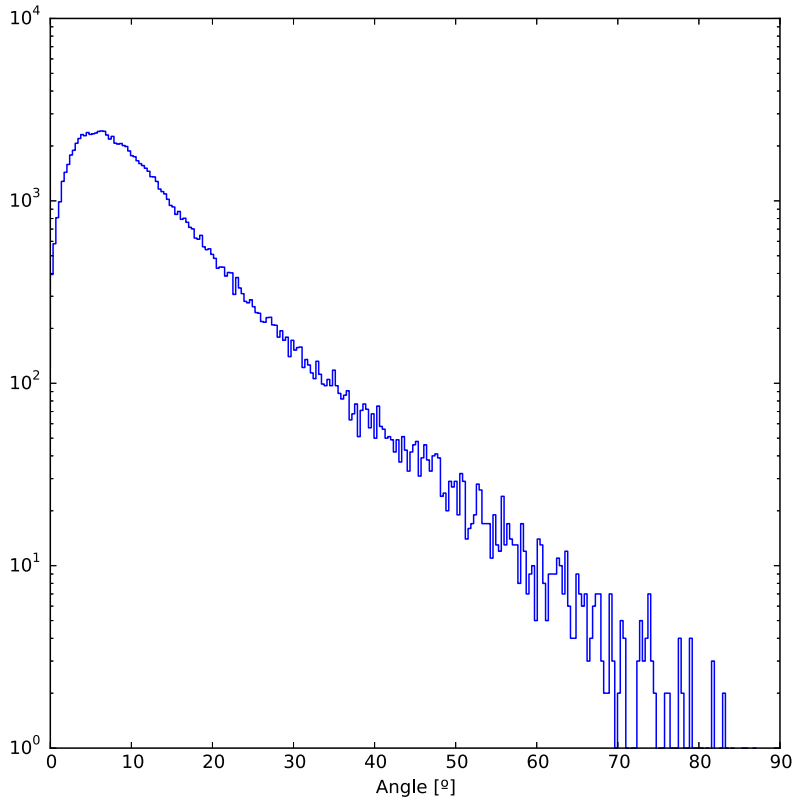

Figure 12: Angular distribution of $15 \mathrm{MeV}$ Au scattered by a $\mathrm{Ta}_{2} \mathrm{O}_{5}$ foil $(369 \mathrm{~nm})$.

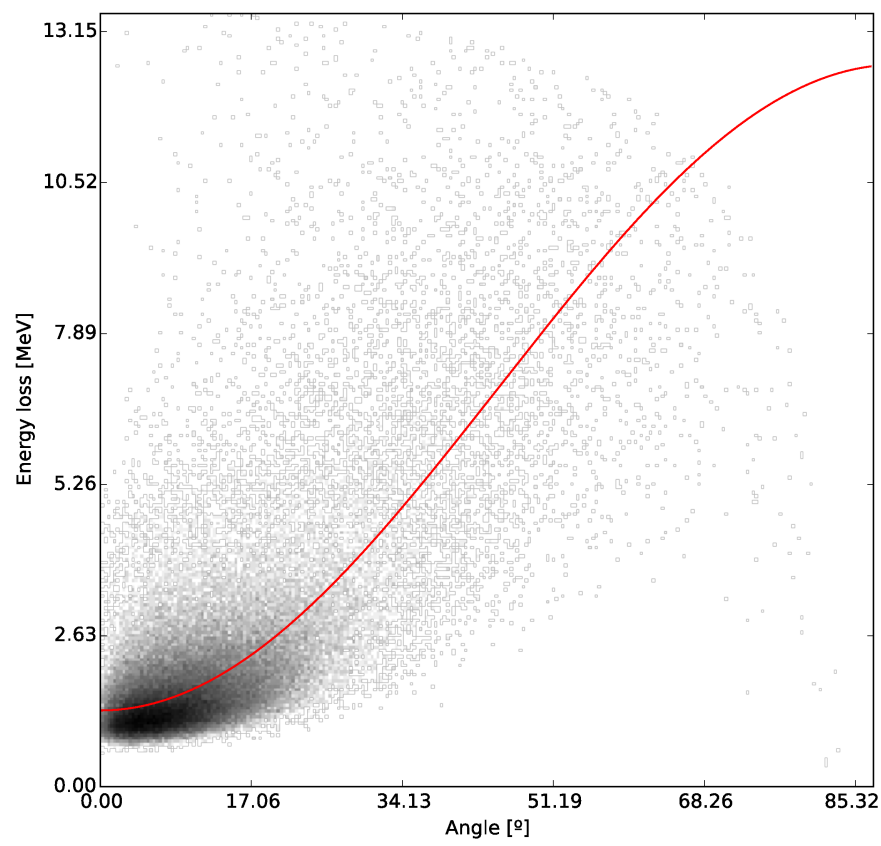

Figure 13: Bidimensional energy loss vs scattering angle distribution of $15 \mathrm{MeV} \mathrm{Au}$ in a $\mathrm{Ta}_{2} \mathrm{O}_{5}$ foil $(369 \mathrm{~nm})$. The color scale is logarithmic. The fitting function follows the means of the asymmetric energy distributions and not the modes, and thus it does not follow the distribution maxima. 


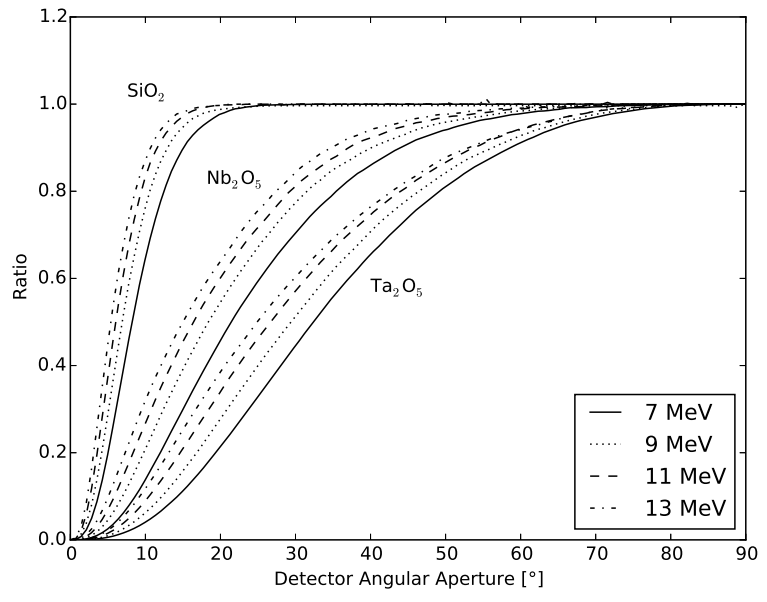

Figure 14: Ratio between the effective nuclear energy loss and the total nuclear energy loss for $15 \mathrm{MeV} \mathrm{Au}$ ions, as a function of the angular aperture of the detector, for different foils.

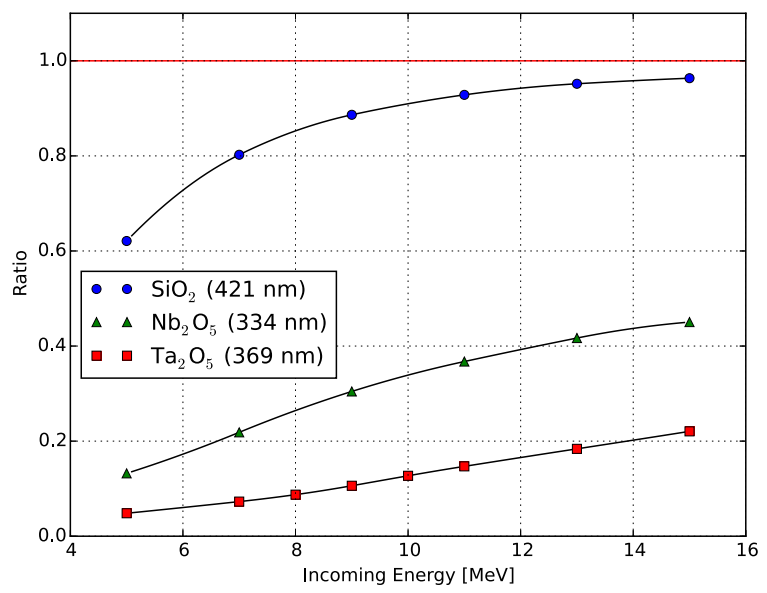

Figure 15: Ratio between the effective nuclear energy loss and the total nuclear energy loss for $15 \mathrm{MeV} \mathrm{Au}$ ions, as measured by a detector with an angular aperture of $13^{\circ}$, for different foils. multiple scattering events (Fig. 11), while the angular distribution is peaked at small scattering angles (Fig. 12). TRIM takes into account multiple scattering. Therefore, the relationship between the mean of the simulated energy distribution and scattering angle, $\Delta E_{\text {eff }}(\theta)$, is the one most relevant to the experiment (Fig. 13). Assuming that the electronic stopping power does not depend on the scattering angle, the calculated nuclear energy loss was corrected by subtracting the calculated electronic energy loss, integrated over the path of the ion inside the foil, from the total energy loss. A convenient fitting function is the same one used to describe the energy loss in a single elastic collision:

$$
\Delta E_{\text {eff }}(\theta)=A-B \cos ^{2} \theta .
$$

The value of the nuclear energy loss needs to be corrected, because the detector is not covering the whole scattering solid angle. The energy loss can be calculated with

$$
\left.\frac{\mathrm{d} E}{\mathrm{~d} x}\right|_{\mathrm{n}}\left(E_{i}\right)=N \int_{T_{\min }}^{T_{\max }} T \sigma_{\mathrm{n}}\left(E_{i}, T\right) \mathrm{d} T
$$

where $N$ is the target number density, $T$ is the energy transfer, and $\sigma$ is the cross section [81]. The energy transfer can be written as $T(\alpha)$, as it depends on the scattering angle $\alpha$, thus we can rewrite the expression as

$$
\left.\frac{\mathrm{d} E}{\mathrm{~d} x}\right|_{\mathrm{n}}\left(E_{i}\right)=N \int_{\alpha_{\min }}^{\alpha_{\max }} T(\alpha) \sigma\left(E_{i}, T(\alpha)\right) \frac{\mathrm{d} T}{\mathrm{~d} \alpha} \mathrm{d} \alpha
$$

i.e. as an integral over the scattering angle. Since we are selecting only part of the forward solid angle, we are not probing the whole stopping power but only a part which we will call effective nuclear energy loss. The ratio, $R$, between the effective nuclear energy loss and the total nuclear energy loss, as measured by a detector with angular aperture $\Theta$ (Figs. 14 and 15) is:

$$
R=\frac{S_{\mathrm{eff}}^{\mathrm{n}}}{S^{\mathrm{n}}}=\frac{\int_{0}^{2 \pi} \mathrm{d} \varphi \int_{0}^{\Theta} \mathrm{d} \theta \sin \theta f(\theta) \Delta E_{\mathrm{eff}}(\theta)}{\int_{0}^{2 \pi} \mathrm{d} \varphi \int_{0}^{\pi} \mathrm{d} \theta \sin \theta f(\theta) \Delta E_{\mathrm{eff}}(\theta)}
$$

where $f(\theta)$ is the angular distribution of the energy loss.

\section{Measurements}

\subsection{Experimental procedure}

The electronic stopping power of $\mathrm{O}, \mathrm{Si}$, Ti and $\mathrm{Au}$ was measured in three foils: $\mathrm{SiO}_{2}, \mathrm{Nb}_{2} \mathrm{O}_{5}$, and $\mathrm{Ta}_{2} \mathrm{O}_{5}$. These materials are important in the fabrication of microelectronic devices, due to their practical applications [70]. Selfsupporting foils were produced via Physical Vapor Deposition (PVD) by combining a conventional magnetron sputtering cathode and a solid-state cesium injector to modify the magnetron sputtering process (Luxel Corporation, Washington) [70].

The He beam was generated by a Radio Frequency (RF) charge exchange ion source (Alphatross). The other beams 


\begin{tabular}{ccccc}
\hline Foil & $\begin{array}{c}T \\
{\left[\mu \mathrm{g} / \mathrm{cm}^{2}\right]}\end{array}$ & $\begin{array}{c}T[\mathrm{~nm}] \\
\text { (nom.) }\end{array}$ & $\begin{array}{c}T[\mathrm{~nm}] \\
(\text { meas.) }\end{array}$ & $\begin{array}{c}\varrho \\
{\left[\mathrm{g} / \mathrm{cm}^{3}\right]}\end{array}$ \\
\hline $\mathrm{SiO}_{2}$ & $92.8 \pm 1.7(1.9 \%)$ & 416.0 & 420.8 & 2.203 \\
$\mathrm{Nb}_{2} \mathrm{O}_{5}$ & $153.4 \pm 2.6(1.7 \%)$ & 360.1 & 333.6 & 4.60 \\
$\mathrm{Ta}_{2} \mathrm{O}_{5}$ & $301.5 \pm 4.5(1.5 \%)$ & 348.8 & 368.6 & 8.18 \\
\hline
\end{tabular}

Table 1: Measured foil thicknesses, $T$, expressed in $\mu \mathrm{g} / \mathrm{cm}^{2}$ and nanometers, and nominal values given by the vendor. The theoretical densities, $\varrho$, are the values used to calculate the thickness measured in nanometers. An additional $2 \%$ uncertainty is added to these values due to the SRIM stopping power uncertainty.

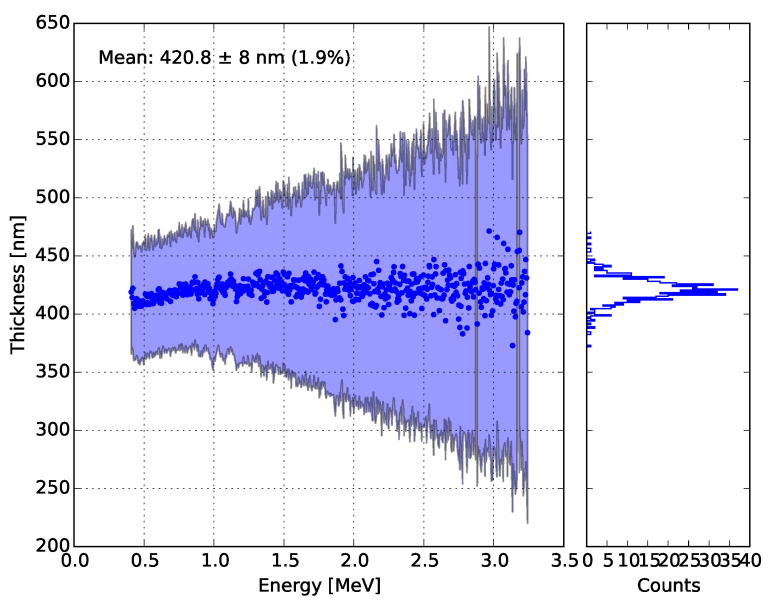

Figure 16: Measured thickness of the $\mathrm{SiO}_{2}$ foil, from energy loss measurements of He and SRIM predictions. [15].

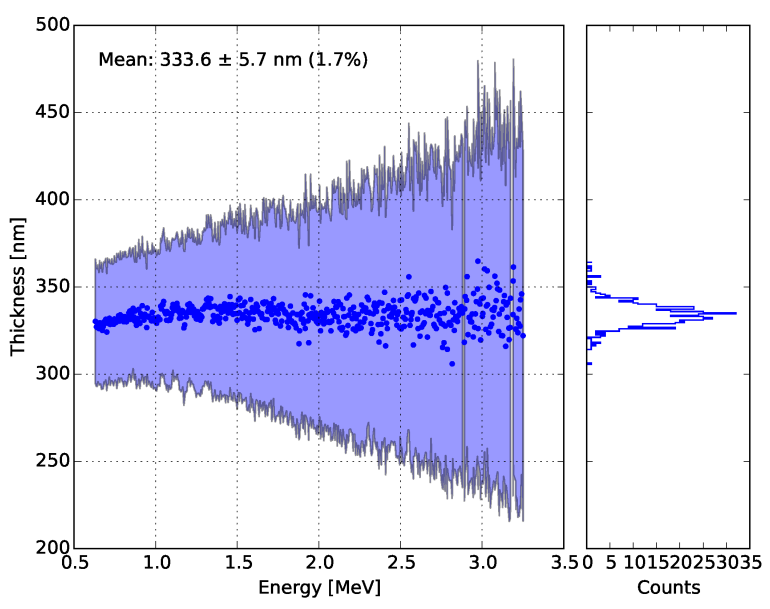

Figure 17: Measured thickness of the $\mathrm{Nb}_{2} \mathrm{O}_{5}$ foil, from energy loss measurements of He and SRIM predictions. [15].

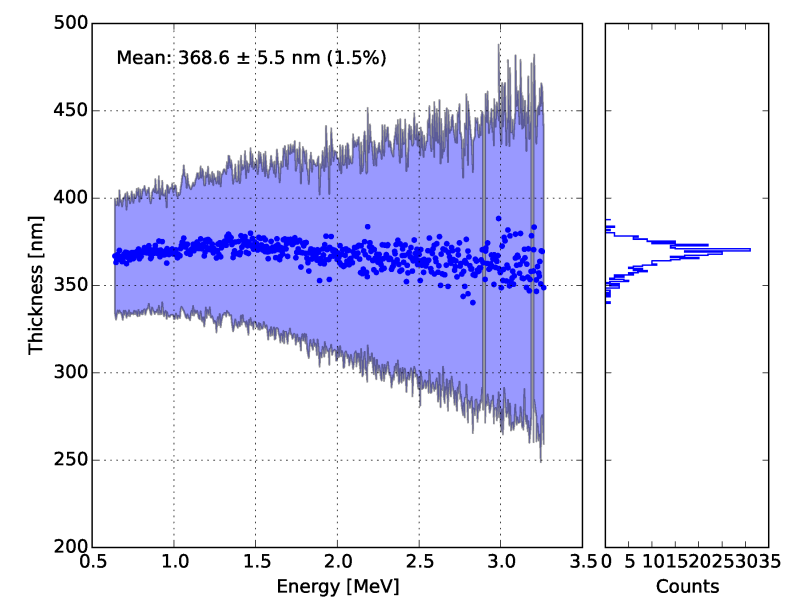

Figure 18: Measured thickness of the $\mathrm{Ta}_{2} \mathrm{O}_{5}$ foil, from energy loss measurements of He and SRIM predictions. [15].

were generated with a Source of Negative Ions by Cesium Sputtering (SNICS) II from solid cathodes [45]. The beams were accelerated by a $3 \mathrm{MV}$ Pelletron accelerator, installed at the UT-ORNL Ion Beam Materials Laboratory (IBML) - a multifunctional facility at the University of Tennessee, Knoxville in Knoxville, Tennessee, USA [45]. Bulk gold was used as a scattering target to optimize the energy range. The detection system comprised a ToF-E detector with two carbon foil time detectors and a silicon detector. The foils were mounted on a push-rod in front of the Si detector allowing several measurements to be made without breaking the vacuum. The distance between the two carbon foils was $77.3 \pm 0.2 \mathrm{~cm}$, the carbon foil densities were $10 \mu \mathrm{g} / \mathrm{cm}^{2}$, the frame on which the foils were mounted is of the type (b) morphology of Fig. 3. The ToF calibrations were performed for each measurement using the ERDA signals from multi-elemental samples, and also by employing an ORTEC Model 462 Time Calibrator. The slope of the calibration line was consistent between experiments performed at different times.

\subsection{Results}

The thickness of the stopping foils was determined by normalizing the energy loss SRIM values for He (Figs. 1618). The results shown in Figs. 19-21 are the determined stopping powers for Helium in the three foils. To compare the results with the nominal values given by the vendor, the measured thicknesses were multiplied by the theoretical densities of the foil materials (Table 1). It is worth mentioning that the uncertainty in the SRIM He stopping powers contributed $3.5 \%$ to the total uncertainty [15]. The measured values are not compatible with the nominal ones, likely because the true densities were not known.

The high energy tail effect, discussed in sec. 4.3, is noticeable. Therefore, the stopping power was measured with the energy detector calibrated both to the mode and mean of the distribution. Both results are presented and 


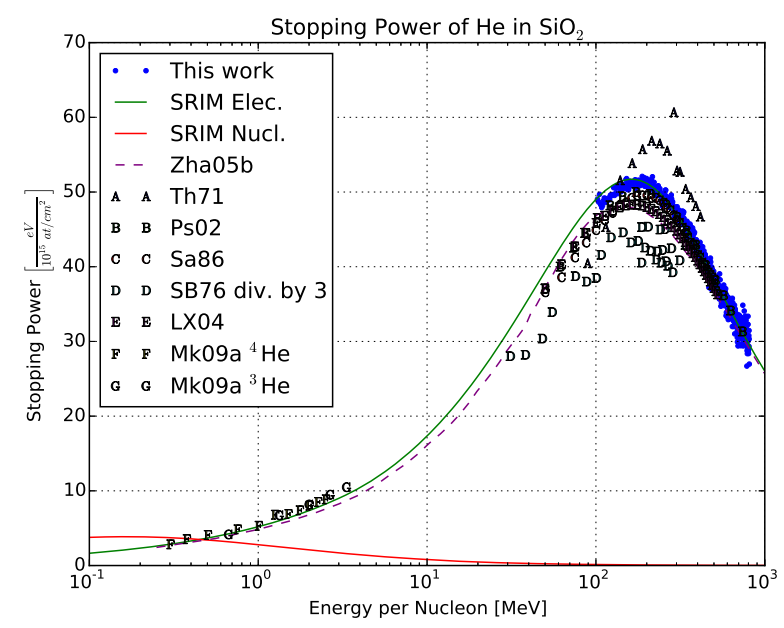

Figure 19: Electronic stopping power of helium in $\mathrm{SiO}_{2}$. The presented data are a consistency check of out method to verify that they are compatible in shape with the SRIM prediction, the uncertainty is $2.2 \%$. The foil thickness is determined by SRIM prediction. References: Zha05b [62], Th71 [82], Ps02 [83], Sa86 [84], SB76 [85] divided by 3 as suggested in [86], LX04 [87], and Mk09a [88].

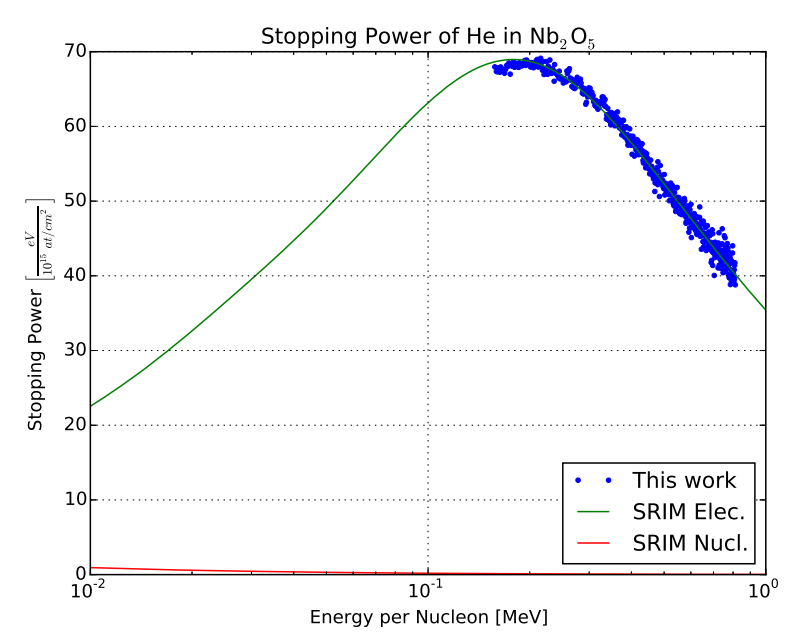

Figure 20: Electronic stopping power of helium in $\mathrm{Nb}_{2} \mathrm{O}_{5}$. The presented data are a consistency check of out method to verify that they are compatible in shape with the SRIM prediction, the uncertainty is $2.2 \%$. The foil thickness is determined by SRIM prediction. discussed. The average uncertainty on the energy losses is less than $1 \%$ for $\mathrm{He}, 2 \%$ for the ions lighter than $\mathrm{Au}$, and $5 \%$ for Au. The propagated uncertainties for the stopping power values are $4.3 \%$ and $6.0 \%$ for the lighter ions and for $\mathrm{Au}$ ions, respectively.

\subsubsection{Oxygen}

For oxygen ions, the nuclear stopping power is negligible and no nuclear stopping correction is needed. Figs. 22-24 show that calibrating the energy with the mean of the energy distribution results in a stopping power for $\mathrm{SiO}_{2}$ that is compatible with the SRIM prediction. On the other hand, for $\mathrm{Nb}_{2} \mathrm{O}_{5}$ and $\mathrm{Ta}_{2} \mathrm{O}_{5}$, the calibration with the mode agrees better with SRIM. For $\mathrm{Ta}_{2} \mathrm{O}_{5}$, the data agree with other published results in the literature, within the variance of all reported data. The SRIM predictions underestimate these results by up to $8 \%$.

\subsubsection{Silicon}

For silicon ions, the calibration with the mode gives results that better agree with the SRIM predictions and with previously published data (Figs. 25-27). The SRIM predictions deviate from the data by up to $6 \%$.

\subsubsection{Titanium}

For the two heaviest titanium foils, the calibration with the mode, again, gives results that agree better with the SRIM predictions (Figs. 28-30). While with the $\mathrm{SiO}_{2}$ foil, the prediction is midway between the two estimates. The calibration with the mean can be off by up to $9 \%$ from the SRIM prediction, while the mode calibration shows good agreement.

\subsubsection{Gold}

In the energy range of interest, $\mathrm{Au}$ ions has a nuclear stopping power comparable with the electronic one; therefore the nuclear stopping power was subtracted from the total stopping power in the manner discussed in sec. 4.5. After this correction, the calibration with the mean agrees better with the SRIM predictions, while the mode calibration was off by up to the $30 \%$. It is worth bearing in mind that SRIM is usually less reliable at calculating electronic stopping powers for heavy elements than for light elements. Therefore, heavy ion SRIM values should only be compared to experimental data with caution. Indeed, according to [77], SRIM simulations overestimate the electronic stopping power of $\mathrm{Au}$ in $\mathrm{SiC}$. This would almost suggest that the calibration with the mode is actually more accurate.

\section{Conclusions}

A review of the techniques for measuring electronic stopping powers of ions in matter was presented. Of these techniques, the time-of-flight method was applied in the measurement of stopping powers for several oxide films at 


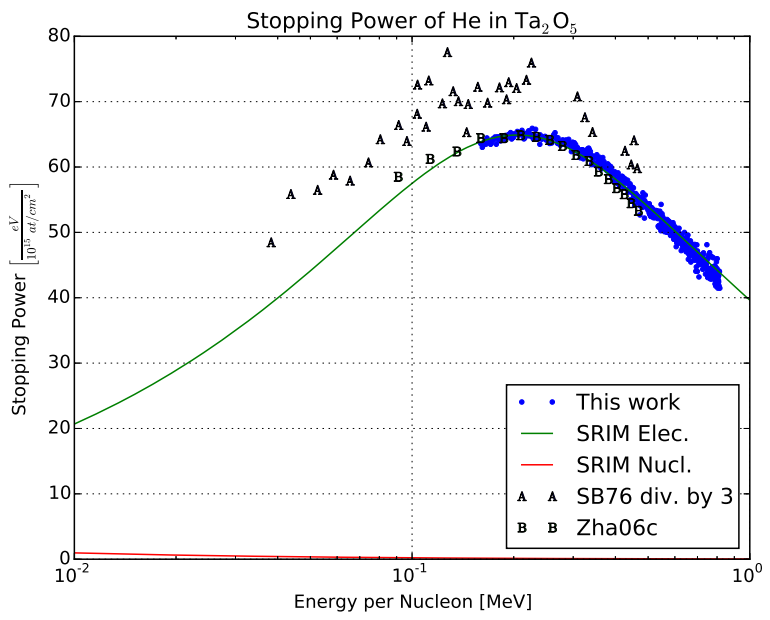

Figure 21: Electronic stopping power of helium in $\mathrm{Ta}_{2} \mathrm{O}_{5}$. The presented data are a consistency check of out method to verify that they are compatible in shape with the SRIM prediction, the uncertainty is $2.2 \%$. The foil thickness is determined by SRIM prediction. References: SB76 [85] divided by 3 as suggested in [86], and Zha06c [70].

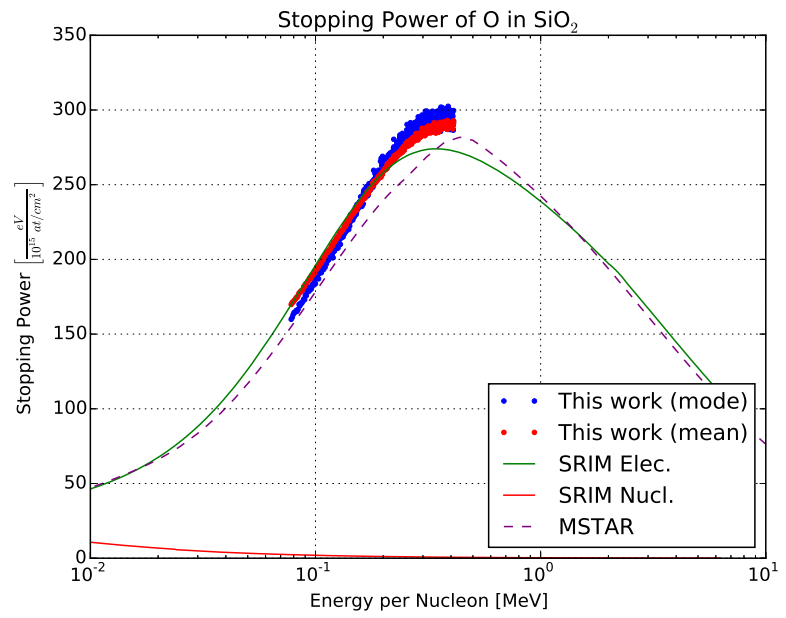

Figure 22: Electronic stopping power of oxygen in $\mathrm{SiO}_{2}$, the uncertainty is $4.3 \%$.

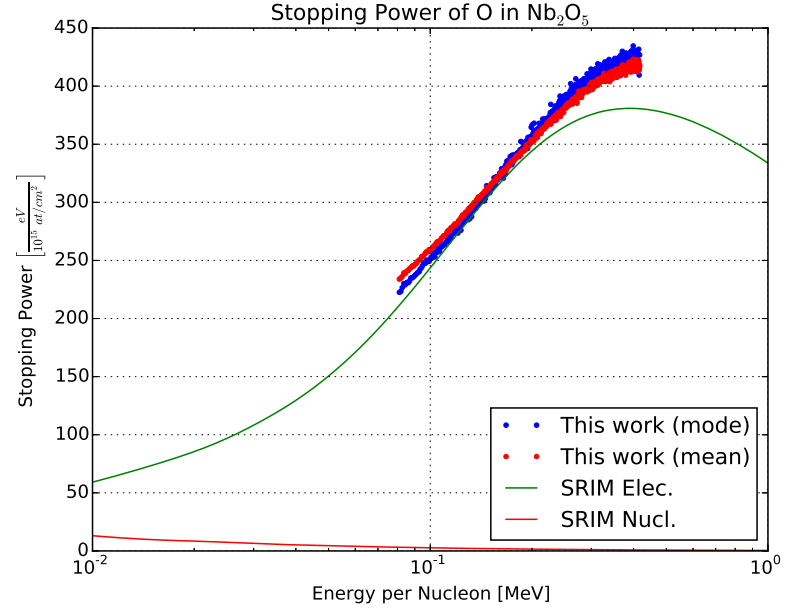

Figure 23: Electronic stopping power of oxygen in $\mathrm{Nb}_{2} \mathrm{O}_{5}$, the uncertainty is $4.3 \%$.

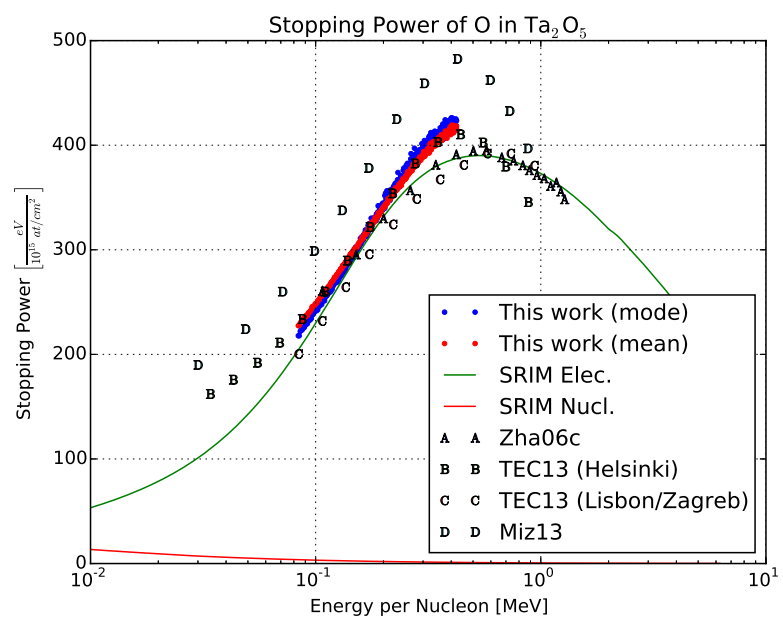

Figure 24: Electronic stopping power of oxygen in $\mathrm{Ta}_{2} \mathrm{O}_{5}$, the uncertainty is $4.3 \%$. References: Zha06c [70], TEC13 and Miz13 [39].

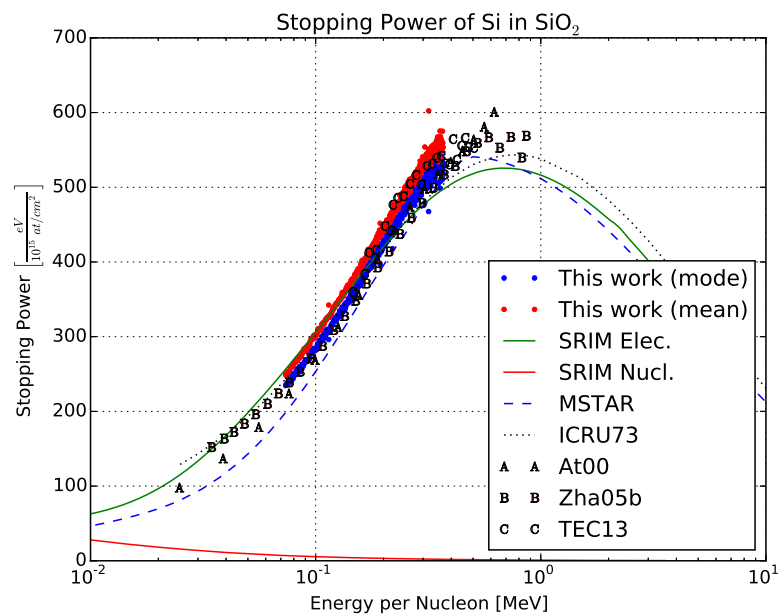

Figure 25: Electronic stopping power of silicon in $\mathrm{SiO}_{2}$, the uncertainty is 4.3\%. References: At00 [89], Zha05b [62], and TEC13 [39]. 


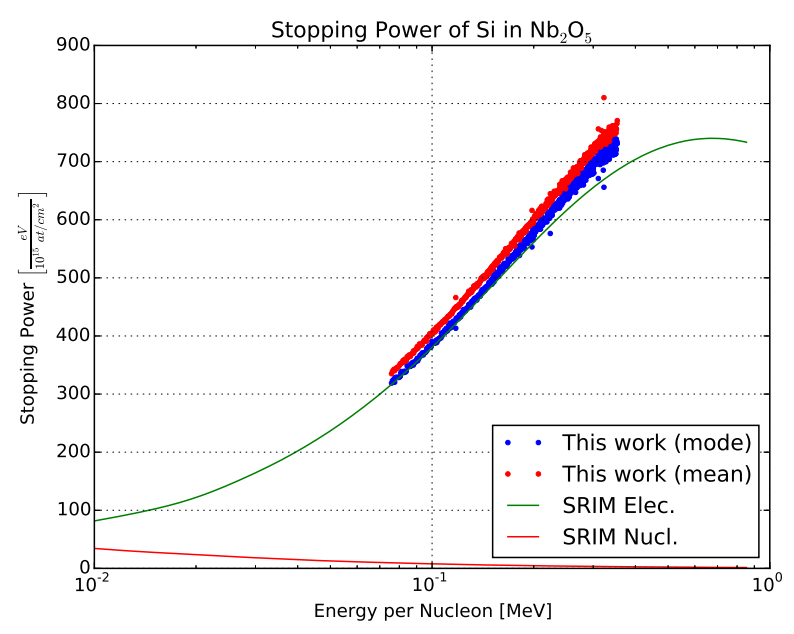

Figure 26: Electronic stopping power of silicon in $\mathrm{Nb}_{2} \mathrm{O}_{5}$, the uncertainty is $4.3 \%$.

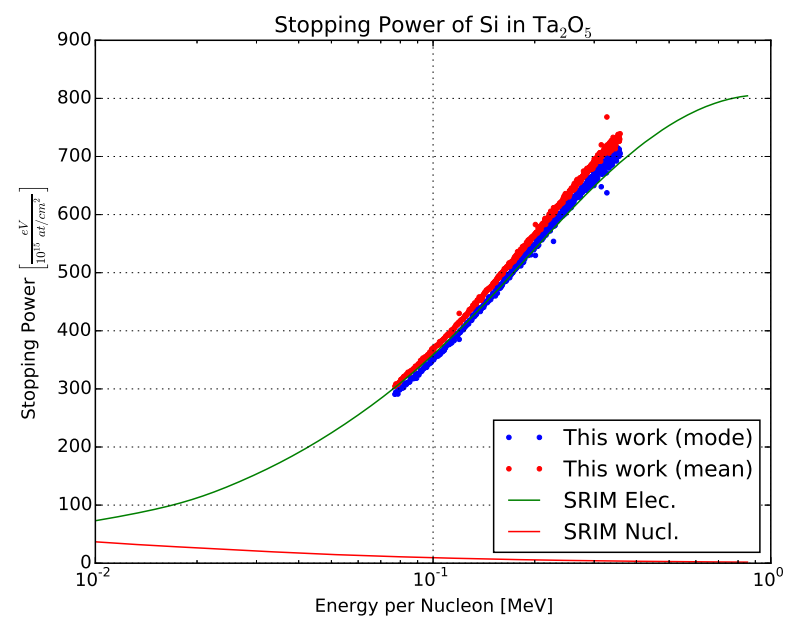

Figure 27: Electronic stopping power of silicon in $\mathrm{Ta}_{2} \mathrm{O}_{5}$, the uncertainty is $4.3 \%$.

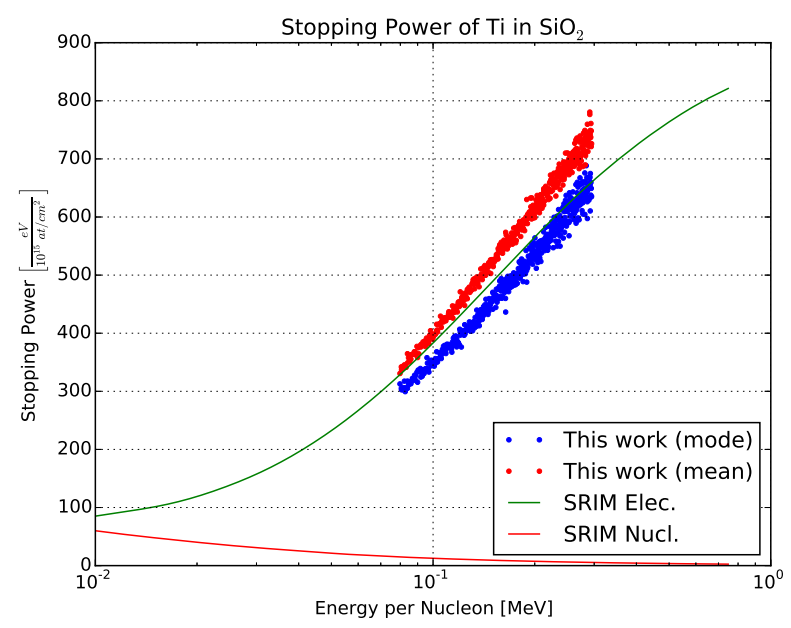

Figure 28: Electronic stopping power of titanium in $\mathrm{SiO}_{2}$, the uncertainty is $4.3 \%$

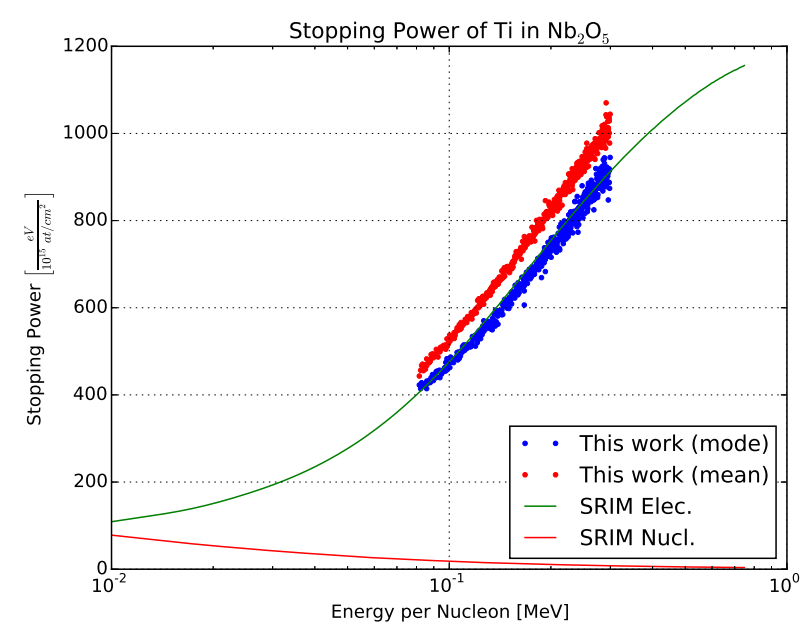

Figure 29: Electronic stopping power of titanium in $\mathrm{Nb}_{2} \mathrm{O}_{5}$, the uncertainty is $4.3 \%$

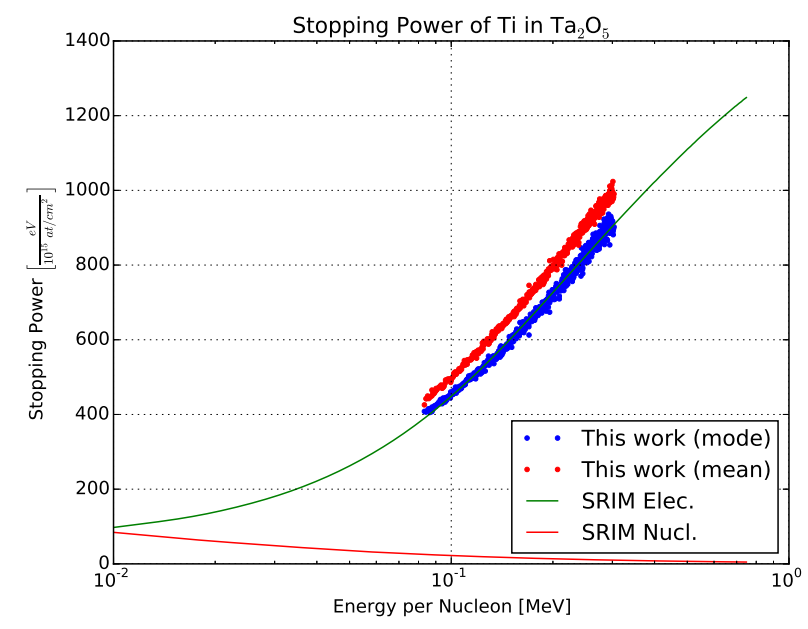

Figure 30: Electronic stopping power of titanium in $\mathrm{Ta}_{2} \mathrm{O}_{5}$, the uncertainty is $4.3 \%$

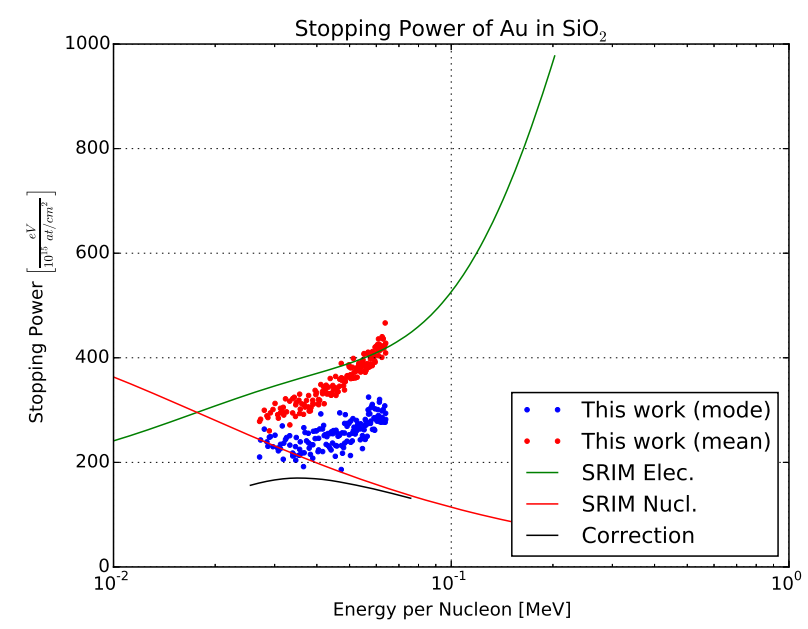

Figure 31: Electronic stopping power of gold in $\mathrm{SiO}_{2}$, the uncertainty is $6.0 \%$ 


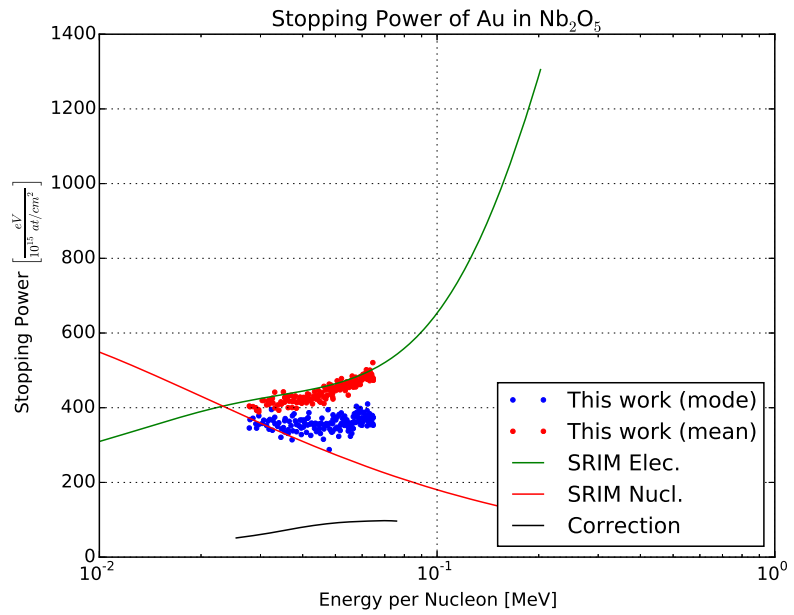

Figure 32: Electronic stopping power of gold in $\mathrm{Nb}_{2} \mathrm{O}_{5}$, the uncertainty is $6.0 \%$

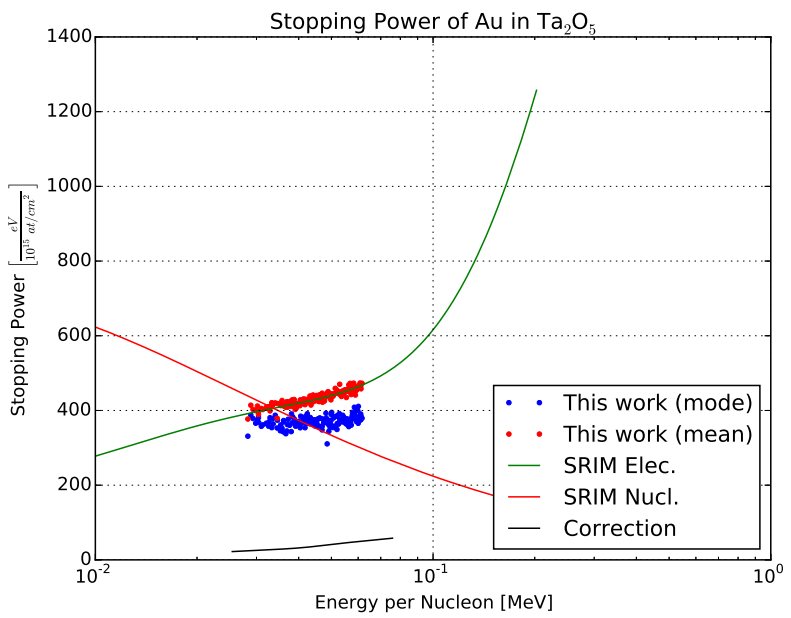

Figure 33: Electronic stopping power of gold in $\mathrm{Ta}_{2} \mathrm{O}_{5}$, the uncertainty is $6.0 \%$ the Ion Beam Materials Laboratory at the University of Tennessee, Knoxville. The measured values were found to agree with previously published data. New stopping power values were compared to the predictions of SRIM. For Au ions, the nuclear energy loss, as calculated by SRIM, was subtracted from the measured energy loss to determine the electronic energy loss. In calibrating the energy of the system, an asymmetric ion energy peak was dealt with through two different methods. In the first, the mode of the distribution was assumed to correspond to the ion energy, while in the second, the mean was taken as the energy. There is not a simple solution for this ambiguity, as some experimental data showed better agreement with SRIM with one method and other data with the other method. Moreover, for heavy ion stopping powers, the SRIM prediction should not be used to benchmark accuracy of a particular measurement.

\section{Acknowledgments}

C. L. Fontana was supported by the U.S. DOE, BES, MSED in the development and demonstration of unique capabilities for damage accumulation studies, and by ORNL LDRD for the ToF-ERDA development.

\section{References}

[1] Y. Wang, M. Nastasi (Eds.), Handbook of Modern Ion Beam Materials Analysis, 2nd Edition, Materials Research Society, Warrendale, Pennsylvania, 2010.

[2] J. Deasy, ICRU Report 49, Stopping Powers and Ranges for Protons and Alpha Particles, Medical Physics 21 (5) (1994) 709710. doi:10.1118/1.597176. URL http://dx.doi.org/10.1118/1.597176

[3] Stopping of Ions Heavier than Helium, Journal of the ICRU 5 (1) (2005) iii-viii. doi:10.1093/jicru/ndi002. URL http://dx.doi.org/10.1093/jicru/ndi002

[4] Y. Zhang, W. J. Weber, Response of materials to single ion events, Nuclear Instruments and Methods in Physics Research Section B: Beam Interactions with Materials and Atoms 267 (89) (2009) 1705-1712. doi:10.1016/j.nimb.2009.01.104. URL http://dx.doi.org/10.1016/j.nimb.2009.01.104

[5] W. J. Weber, D. M. Duffy, L. Thomé, Y. Zhang, The role of electronic energy loss in ion beam modification of materials, Current Opinion in Solid State and Materials Science 19 (1) (2015) 1-11. doi:10.1016/j.cossms.2014.09.003. URL http://dx.doi.org/10.1016/j.cossms.2014.09.003

[6] A. Simon, N. Pessoa Barradas, A. Bergmaier, M. Msimanga, I. Bogdanovic Radovic, J. Räisänen, T. Sajavaara, New experimental molecular stopping cross section data of $\mathrm{Al} 2 \mathrm{O} 3$, for heavy ions, Nuclear Instruments and Methods in Physics Research Section B: Beam Interactions with Materials and Atoms 332 (2014) 341-345. doi:10.1016/j.nimb.2014.02.092. URL http://dx.doi.org/10.1016/j.nimb.2014.02.092

[7] N. P. Barradas, E. Alves, M. Fonseca, Z. Siketić, I. Bogdanović Radović, Stopping power of $\mathrm{C}, \mathrm{O}$ and $\mathrm{Cl}$ in tantalum oxide, Nuclear Instruments and Methods in Physics Research Section B: Beam Interactions with Materials and Atoms 332 (2014) 152-155. doi:10.1016/j.nimb.2014.02.050. URL http://dx.doi.org/10.1016/j.nimb.2014.02.050

[8] C. H. Chen, Y. Zhang, E. Fu, Y. Wang, M. L. Crespillo, C. Liu, S. Shannon, W. J. Weber, Irradiation-induced microstructural change in helium-implanted single crystal and nano-engineered $\mathrm{SiC}$, Journal of Nuclear Materials 453 (1-3) (2014) 280-286. 
doi:10.1016/j.jnucmat.2014.07.020.

URL http://dx.doi.org/10.1016/j.jnucmat.2014.07.020

[9] Y. Zhang, A. Debelle, A. Boulle, P. Kluth, F. Tuomisto, Advanced techniques for characterization of ion beam modified materials, Current Opinion in Solid State and Materials Science 19 (1) (2015) 19-28. doi:10.1016/j.cossms.2014.09.007. URL http://dx.doi.org/10.1016/j.cossms.2014.09.007

[10] Y. Zhang, W. Weber, Validity of Bragg's rule for heavyion stopping in silicon carbide, Physical Review B 68 (23). doi:10.1103/physrevb.68.235317.

URL http://dx.doi.org/10.1103/physrevb.68.235317

[11] Y. Zhang, W. Weber, C. Wang, Electronic stopping powers in silicon carbide, Physical Review B 69 (20) (2004) 205201+. doi:10.1103/physrevb.69.205201.

URL http://dx.doi.org/10.1103/physrevb.69.205201

[12] C. Angulo, T. Delbar, J.-S. Graulich, P. Leleux, Stopping power measurements: Implications in nuclear astrophysics, AIP Conference Proceedings 495 (1) (1999) 381-384. doi:10.1063/1.1301826.

URL http://dx.doi.org/10.1063/1.1301826

[13] N. V. Kuznetsov, R. A. Nymmik, N. M. Sobolevsky, Estimates of radiation effect for a spacecraft on the Earth-MarsEarth route, Advances in Space Research 30 (4) (2002) 985-988. doi:10.1016/s0273-1177(02)00163-1.

URL http://dx.doi.org/10.1016/s0273-1177 (02)00163-1

[14] B. Schaffner, E. Pedroni, The precision of proton range calculations in proton radiotherapy treatment planning: experimental verification of the relation between CT-HU and proton stopping power, Physics in Medicine and Biology 43 (6) (1998) 15791592. doi:10.1088/0031-9155/43/6/016.

URL http://dx.doi.org/10.1088/0031-9155/43/6/016

[15] J. F. Ziegler, M. D. Ziegler, J. P. Biersack, SRIM - The stopping and range of ions in matter (2010), Nuclear Instruments and Methods in Physics Research Section B: Beam Interactions with Materials and Atoms 268 (11-12) (2010) 1818-1823. doi:10.1016/j.nimb.2010.02.091.

URL http://dx.doi.org/10.1016/j.nimb.2010.02.091

[16] H. Paul, Recent results in stopping power for positive ions, and some critical comments, Nuclear Instruments and Methods in Physics Research Section B: Beam Interactions with Materials and Atoms 268 (22) (2010) 3421-3425. doi:10.1016/j.nimb.2010.09.001.

URL http://dx.doi.org/10.1016/j.nimb.2010.09.001

[17] P. Bauer, How to measure absolute stopping cross sections by backscattering and by transmission methods, Nuclear Instruments and Methods in Physics Research Section B: Beam Interactions with Materials and Atoms 27 (2) (1987) 301-314. doi:10.1016/0168-583x(87)90569-6.

URL http://dx.doi.org/10.1016/0168-583x(87)90569-6

[18] G. Lulli, E. Albertazzi, M. Bianconi, G. G. Bentini, R. Nipoti, R. Lotti, Determination of He electronic energy loss in crystalline Si by Monte-Carlo simulation of Rutherford backscattering-channeling spectra, Nuclear Instruments and Methods in Physics Research Section B: Beam Interactions with Materials and Atoms 170 (1-2) (2000) 1-9. doi:10.1016/s0168$583 x(00) 00089-6$. URL http://dx.doi.org/10.1016/s0168-583x(00) 00089-6

[19] N. P. Barradas, C. Jeynes, R. P. Webb, E. Wendler, Accurate determination of the stopping power of in Si using Bayesian inference, Nuclear Instruments and Methods in Physics Research Section B: Beam Interactions with Materials and Atoms 194 (1) (2002) 15-25. doi:10.1016/s0168-583x(02)00494-9. URL http://dx.doi.org/10.1016/s0168-583x(02) 00494-9

[20] G. Azevedo, M. Behar, J. Dias, P. Grande, D. da Silva, G. Schiwietz, Random and channeling stopping powers of $\mathrm{He}$ and Li ions in Si, Physical Review B 65 (7) (2002) 075203+. doi:10.1103/physrevb.65.075203.

URL http://dx.doi.org/10.1103/physrevb.65.075203

[21] H. R. Andrews, W. N. Lennard, I. V. Mitchell, D. Ward, D. Phillips, R. B. Walker, N. Rud, Low Energy Stopping Powers Determined by Time of Flight Techniques, Nuclear
Science, IEEE Transactions on 26 (1) (1979) 1326-1330. doi:10.1109/tns.1979.4330380.

URL http://dx.doi.org/10.1109/tns.1979.4330380

[22] P. Belery, T. Delbar, G. Gregoire, Multiple scattering and energy straggling of heavy ions in solid targets, Nuclear Instruments and Methods 179 (1) (1981) 1-9. doi:10.1016/0029$554 \mathrm{x}(81) 91154-\mathrm{x}$.

URL http://dx.doi.org/10.1016/0029-554x (81)91154-x

[23] P. Mertens, How to measure absolute stopping cross sections by backscattering and transmission methods, Nuclear Instruments and Methods in Physics Research Section B: Beam Interactions with Materials and Atoms 27 (2) (1987) 315-322. doi:10.1016/0168-583x(87)90570-2.

URL http://dx.doi.org/10.1016/0168-583x (87)90570-2

[24] J. Räisänen, U. Wätjen, A. J. M. Plompen, F. Munnik, Stopping power determinations by the transmission technique, $\mathrm{Nu}$ clear Instruments and Methods in Physics Research Section B: Beam Interactions with Materials and Atoms 118 (1-4) (1996) 1-6. doi:10.1016/0168-583x(95)01185-4. URL http://dx.doi.org/10.1016/0168-583x(95)01185-4

[25] P. Mertens, P. Bauer, D. Semrad, Proton stopping powers in $\mathrm{Al}, \mathrm{Ni}, \mathrm{Cu}, \mathrm{Ag}$ and $\mathrm{Au}$ measured comparatively on identical targets in backscattering and transmission geometry, Nuclear Instruments and Methods in Physics Research Section B: Beam Interactions with Materials and Atoms 15 (1-6) (1986) 91-95. doi:10.1016/0168-583x(86)90260-0.

URL http://dx.doi.org/10.1016/0168-583x (86) 90260-0

[26] J. Jokinen, Stopping powers of $\mathrm{C}, \mathrm{Al}$ and $\mathrm{Cu}$ for use in ERDA analyses with probing $\mathrm{MeV}$ energy 197Au ions, Nuclear Instruments and Methods in Physics Research Section B: Beam Interactions with Materials and Atoms 124 (4) (1997) 447-452. doi:10.1016/s0168-583x(97)00087-6.

URL http://dx.doi.org/10.1016/s0168-583x(97)00087-6

[27] Y. Zhang, G. Possnert, H. J. Whitlow, Measurements of the mean energy-loss of swift heavy ions in carbon with high precision, Nuclear Instruments and Methods in Physics Research Section B: Beam Interactions with Materials and Atoms 183 (12) (2001) 34-47. doi:10.1016/s0168-583x(00)00684-4.

URL http://dx.doi.org/10.1016/s0168-583x(00) 00684-4

[28] D. Ward, H. R. Andrews, I. V. Mitchell, W. N. Lennard, R. B. Walker, N. Rud, Systematics for the Z1-oscillation in stopping powers of various solid materials, Can. J. Phys. 57 (5) (1979) 645-656. doi:10.1139/p79-092. URL http://dx.doi.org/10.1139/p79-092

[29] W. N. Lennard, H. R. Andrews, M. Freeman, I. V. Mitchell, D. Phillips, D. A. S. Walker, D. Ward, Time-of-flight system for slow heavy ions, Nuclear Instruments and Methods in Physics Research 203 (1-3) (1982) 565-570. doi:10.1016/01675087(82)90675-5.

URL http://dx.doi.org/10.1016/0167-5087 (82)90675-5

[30] W. H. Trzaska, T. Alanko, V. Lyapin, J. Räisänen, A novel method for obtaining continuous stopping power curves, Nuclear Instruments and Methods in Physics Research Section B: Beam Interactions with Materials and Atoms 183 (3-4) (2001) 203-211. doi:10.1016/s0168-583x(01)00728-5.

URL http://dx.doi.org/10.1016/s0168-583x(01)00728-5

[31] T. Alanko, W. H. Trzaska, V. Lyapin, J. Räisänen, G. Tiourine, A. Virtanen, Simultaneous wide-range stopping power determination for several ions, Nuclear Instruments and Methods in Physics Research Section B: Beam Interactions with Materials and Atoms 190 (1-4) (2002) 60-63. doi:10.1016/s0168$583 x(01) 01289-7$. URL http://dx.doi.org/10.1016/s0168-583x(01) 01289-7

[32] H. J. Whitlow, H. Timmers, R. G. Elliman, T. D. M. Weijers, Y. Zhang, J. Uribastera, D. John O'Connor, Measurements of Si ion stopping in amorphous silicon, Nuclear Instruments and Methods in Physics Research Section B: Beam Interactions with Materials and Atoms 190 (1-4) (2002) 84-88. doi:10.1016/s0168$583 x(01) 01301-5$.

URL http://dx.doi.org/10.1016/s0168-583x(01) 01301-5

[33] H. Geissel, Y. Laichter, R. Albrecht, T. Kitahara, J. Klabunde, 
P. Strehl, P. Armbruster, A time-of-flight method for stopping power measurements of bunched ion beams, Nuclear Instruments and Methods in Physics Research 206 (3) (1983) 609-612. doi:10.1016/0167-5087(83)90404-0.

URL http://dx.doi.org/10.1016/0167-5087 (83)90404-0

[34] E. Geyer, D. Reschke, K. Freitag, Z1 stopping power oscillation in the nuclear stopping regime as obtained by time-offlight spectroscopy of heavy ions in hydrogen, Nuclear Instruments and Methods in Physics Research Section B: Beam Interactions with Materials and Atoms 15 (1-6) (1986) 81-85. doi:10.1016/0168-583x(86)90258-2.

URL http://dx.doi.org/10.1016/0168-583x(86) 90258-2

[35] K. Freitag, D. Reschke, E. Geyer, Stopping power measurements for low energy ions in gases by time-of-flight spectroscopy, Nuclear Instruments and Methods in Physics Research Section B: Beam Interactions with Materials and Atoms 27 (2) (1987) 344352. doi:10.1016/0168-583x(87)90576-3.

URL http://dx.doi.org/10.1016/0168-583x (87)90576-3

[36] Y. Zhang, G. Possnert, W. J. Weber, Measurement of electronic stopping power of swift heavy ions using high-resolution timeof-flight spectrometer, Applied Physics Letters 80 (24) (2002) 4662-4664. doi:10.1063/1.1486042.

URL http://dx.doi.org/10.1063/1.1486042

[37] K. Jin, Y. Zhang, Z. Zhu, D. A. Grove, H. Xue, J. Xue, W. J. Weber, Electronic stopping powers for heavy ions in $\mathrm{SiC}$ and $\mathrm{SiO} 2$, Journal of Applied Physics 115 (4) (2014) 044903+. doi:10.1063/1.4861642. URL http://dx.doi.org/10.1063/1.4861642

[38] A. Guesmia, H. Ammi, S. Mammeri, A. Dib, C. A. PinedaVargas, M. Msimanga, M. Hedibel, Semi empirical formula for electronic stopping power determination of $24 \mathrm{Mg}, 27 \mathrm{Al}$ and $28 \mathrm{Si}$ ions crossing Formvar foil in the ion energy domain of LSS theory, Radiation Physics and Chemistry 96 (2014) 205-210. doi:10.1016/j.radphyschem.2013.10.003.

URL http://dx.doi.org/10.1016/j.radphyschem.2013.10.003

[39] K. Mizohata, J. Räisänen, J. Keinonen, E. Härkönen, J. Palmans, M. Ritala, Stopping cross sections of atomic layer deposited $\mathrm{Al} 2 \mathrm{O} 3$ and $\mathrm{Ta} 2 \mathrm{O} 5$ and of $\mathrm{Si} 3 \mathrm{~N} 4$ for $12 \mathrm{C}, 16 \mathrm{O}, 35 \mathrm{Cl}$, $79 \mathrm{Br}$ and $127 \mathrm{I}$ ions, Nuclear Instruments and Methods in Physics Research Section B: Beam Interactions with Materials and Atoms 300 (2013) 1-5. doi:10.1016/j.nimb.2013.02.010. URL http://dx.doi.org/10.1016/j.nimb.2013.02.010

[40] A. Javanainen, T. Malkiewicz, J. Perkowski, W. H. Trzaska, A. Virtanen, G. Berger, W. Hajdas, R. HarboeSorensen, H. Kettunen, V. Lyapin, M. Mutterer, A. Pirojenko, I. Riihimaki, T. Sajavaara, G. Tyurin, H. J. Whitlow, Linear Energy Transfer of Heavy Ions in Silicon, Nuclear Science, IEEE Transactions on 54 (4) (2007) 1158-1162. doi:10.1109/tns.2007.895121.

URL http://dx.doi.org/10.1109/tns.2007.895121

[41] D. Desmarais, J. L. Duggan, An undergraduate -particle timeof-flight experiment for determining the mean excitation energy for electronic stopping power of $\mathrm{Al}, \mathrm{Cu}, \mathrm{Ag}$, and $\mathrm{Au}$, American Journal of Physics 52 (5) (1984) 408-411. doi:10.1119/1.13626. URL http://dx.doi.org/10.1119/1.13626

[42] W. Hong, S. Hayakawa, K. Maeda, S. Fukuda, M. Yanokura, M. Aratani, K. Kimura, Y. Gohshi, I. Tanihata, Development of a high mass-resolution TOF-ERDA system for a wide mass range, Nuclear Instruments and Methods in Physics Research Section B: Beam Interactions with Materials and Atoms 124 (1) (1997) 95-99. doi:10.1016/s0168-583x(97)00081-5. URL http://dx.doi.org/10.1016/s0168-583x (97)00081-5

[43] S. Giangrandi, T. Sajavaara, B. Brijs, K. Arstila, A. Vantomme, W. Vandervorst, Low-energy heavy-ion TOF-ERDA setup for quantitative depth profiling of thin films, Nuclear Instruments and Methods in Physics Research Section B: Beam Interactions with Materials and Atoms 266 (24) (2008) 5144-5150. doi:10.1016/j.nimb.2008.08.018. URL http://dx.doi.org/10.1016/j.nimb.2008.08.018

[44] M. Msimanga, C. M. Comrie, C. A. Pineda-Vargas, S. Murray, R. Bark, G. Dollinger, A Time of Flight-Energy spec- trometer for stopping power measurements in Heavy IonERD analysis at iThemba LABS, Nuclear Instruments and Methods in Physics Research Section B: Beam Interactions with Materials and Atoms 267 (16) (2009) 2671-2674. doi:10.1016/j.nimb.2009.05.014.

URL http://dx.doi.org/10.1016/j.nimb.2009.05.014

[45] Y. Zhang, M. L. Crespillo, H. Xue, K. Jin, C. H. Chen, C. L. Fontana, J. T. Graham, W. J. Weber, New ion beam materials laboratory for materials modification and irradiation effects research, Nuclear Instruments and Methods in Physics Research Section B: Beam Interactions with Materials and Atoms 338 (2014) 19-30. doi:10.1016/j.nimb.2014.07.028.

URL http://dx.doi.org/10.1016/j.nimb.2014.07.028

[46] R. L. Kavalov, Y. Margaryan, M. G. Panyan, G. A. Papyan, A zero-time detector of charged particles based on secondary electron emission from low density dielectrics, Nuclear Instruments and Methods in Physics Research Section A: Accelerators, Spectrometers, Detectors and Associated Equipment 237 (3) (1985) 543-546. doi:10.1016/0168-9002(85)91064-2. URL http://dx.doi.org/10.1016/0168-9002 (85)91064-2

[47] M. Laitinen, M. Rossi, J. Julin, T. Sajavaara, Time-of-flight Energy spectrometer for elemental depth profiling - Jyväskylä design, Nuclear Instruments and Methods in Physics Research Section B: Beam Interactions with Materials and Atoms 337 (2014) 55-61. doi:10.1016/j.nimb.2014.07.001. URL http://dx.doi.org/10.1016/j.nimb.2014.07.001

[48] A. M. Zebelman, W. G. Meyer, K. Halbach, A. M. Poskanzer, R. G. Sextro, G. Gabor, D. A. Landis, A time-zero detector utilizing isochronous transport of secondary electrons, Nuclear Instruments and Methods 141 (3) (1977) 439-447. doi:10.1016/0029-554x(77)90637-1. URL http://dx.doi.org/10.1016/0029-554x(77)90637-1

[49] Bowman, R. H. Heffner, A novel zero time detector for heavy ion spectroscopy, Nuclear Instruments and Methods 148 (3) (1978) 503-509. doi:10.1016/0029-554x(78)91032-7. URL http://dx.doi.org/10.1016/0029-554x (78)91032-7

[50] F. Busch, W. Pfeffer, B. Kohlmeyer, D. Schüll, F. Pühlhoffer, A position-sensitive transmission time detector, Nuclear Instruments and Methods 171 (1) (1980) 71-74. doi:10.1016/0029$554 \mathrm{x}(80) 90011-7$.

URL http://dx.doi.org/10.1016/0029-554x(80)90011-7

[51] A. Razpet, P. Pelicon, Z. Rupnik, M. Budnar, Development of a time-of-flight telescope for ERDA at the Jožef Stefan Institute, Nuclear Instruments and Methods in Physics Research Section B: Beam Interactions with Materials and Atoms 201 (3) (2003) 535-542. doi:10.1016/s0168-583x(02)01881-5.

URL http://dx.doi.org/10.1016/s0168-583x(02) 01881-5

[52] F. S. Goulding, B. G. Harvey, Identification of Nuclear Particles, Annual Review of Nuclear Science 25 (1) (1975) 167-240. doi:10.1146/annurev.ns.25.120175.001123.

URL http://dx.doi.org/10.1146/annurev.ns.25.120175.001123

[53] C. Kottler, M. Döbeli, F. Glaus, M. Suter, A spectrometer for low energy heavy ion ERDA, Nuclear Instruments and Methods in Physics Research Section B: Beam Interactions with Materials and Atoms 248 (1) (2006) 155-162. doi:10.1016/j.nimb.2006.02.013. URL http://dx.doi.org/10.1016/j.nimb.2006.02.013

[54] S. Giangrandi, B. Brijs, T. Sajavaara, K. Arstila, A. Vantomme, W. Vandervorst, Time-of-flight telescope for heavy-ion RBS, Nuclear Instruments and Methods in Physics Research Section B: Beam Interactions with Materials and Atoms 261 (1-2) (2007) 529-533. doi:10.1016/j.nimb.2007.03.094. URL http://dx.doi.org/10.1016/j.nimb.2007.03.094

[55] J. K. Kim, Y. S. Kim, G. D. Kim, H. W. Choi, H. J. Woo, S. Y. Cho, C. N. Whang, A TOF spectrometer for elastic recoil detection, Nuclear Instruments and Methods in Physics Research Section B: Beam Interactions with Materials and Atoms 140 (34) (1998) 380-388. doi:10.1016/s0168-583x(98)00007-x. URL http://dx.doi.org/10.1016/s0168-583x(98)00007-x

[56] E. Strub, W. Bohne, J. Röhrich, Determination of the energy loss of various elements in metal foils with the 
TOF-ERDA setup at the ISL Berlin, Nuclear Instruments and Methods in Physics Research Section B: Beam Interactions with Materials and Atoms 249 (1-2) (2006) 62-64. doi:10.1016/j.nimb.2006.03.079.

URL http://dx.doi.org/10.1016/j.nimb.2006.03.079

[57] W. Bohne, J. Röhrich, G. Röschert, The Berlin time-of-flight ERDA setupe, Nuclear Instruments and Methods in Physics Research Section B: Beam Interactions with Materials and Atoms 136-138 (1998) 633-637. doi:10.1016/s0168-583x(97)00787-8. URL http://dx.doi.org/10.1016/s0168-583x (97) 00787-8

[58] Y. Zhang, H. J. Whitlow, T. Winzell, I. F. Bubb, T. Sajavaara, K. Arstila, J. Keinonen, Detection efficiency of time-of-flight energy elastic recoil detection analysis systems, Nuclear Instruments and Methods in Physics Research Section B: Beam Interactions with Materials and Atoms 149 (4) (1999) 477-489. doi:10.1016/s0168-583x(98)00963-x. URL http://dx.doi.org/10.1016/s0168-583x (98)00963-x

[59] K. Kroneberger, A. Clouvas, G. Schlüssler, P. Koschar, J. Kemmler, H. Rothard, C. Biedermann, O. Heil, M. Burkhard, K. O. Groeneveld, Secondary electron yields from the entrance and exit surfaces of thin carbon foils induced by penetration of $\mathrm{H}+, \mathrm{H0}$ and $\mathrm{H}+2$ projectiles $(1.2 \mathrm{MeV} / \mathrm{u})$, Nuclear Instruments and Methods in Physics Research Section B: Beam Interactions with Materials and Atoms 29 (4) (1988) 621-626. doi:10.1016/0168-583x(88)90469-7. URL http://dx.doi.org/10.1016/0168-583x(88) 90469-7

[60] D. Ward, H. R. Andrews, I. V. Mitchell, W. N. Lennard, R. B. Walker, Systematic of the Z1-oscillation in stopping powers of various solid materials, Canadian Journal of Physics 57 (1979) 645-656.

[61] M. Döbeli, C. Kottler, F. Glaus, M. Suter, ERDA at the low energy limit, Nuclear Instruments and Methods in Physics Research Section B: Beam Interactions with Materials and Atoms 241 (1-4) (2005) 428-435. doi:10.1016/j.nimb.2005.07.090. URL http://dx.doi.org/10.1016/j.nimb.2005.07.090

[62] Y. Zhang, W. J. Weber, D. E. McCready, D. A. Grove, J. Jensen, G. Possnert, Experimental determination of electronic stopping for ions in silicon dioxide, Applied Physics Letters 87 (10) (2005) 104103+. doi:10.1063/1.2041828. URL http://dx.doi.org/10.1063/1.2041828

[63] Y. Zhang, G. Possnert, Measurements Of Electronic Stopping Power Of Swift Heavy Ions, AIP Conference Proceedings 680 (1) (2003) 90-93. doi:10.1063/1.1619672. URL http://dx.doi.org/10.1063/1.1619672

[64] Y. Zhang, G. Possnert, Electronic stopping power of swift heavy ions in carbon, Nuclear Instruments and Methods in Physics Research Section B: Beam Interactions with Materials and Atoms 190 (1-4) (2002) 69-73. doi:10.1016/s0168-583x(01)01239-3. URL http://dx.doi.org/10.1016/s0168-583x(01)01239-3

[65] M. Msimanga, C. M. Comrie, C. A. Pineda-Vargas, S. Murray, Experimental stopping powers of $\mathrm{Al}, \mathrm{Mg}, \mathrm{F}$ and $\mathrm{O}$ ions in $\mathrm{ZrO} 2$ in the $0.1-0.6 \mathrm{MeV} / \mathrm{u}$ energy range, Nuclear Instruments and Methods in Physics Research Section B: Beam Interactions with Materials and Atoms 268 (11-12) (2010) 1772-1775. doi:10.1016/j.nimb.2010.02.071.

URL http://dx.doi.org/10.1016/j.nimb.2010.02.071

[66] M. Chekirine, H. Ammi, R. K. Choudhury, D. C. Biswas, S. Tobbeche, Stopping power measurements for $16 \mathrm{O}, 19 \mathrm{~F}$ and $28 \mathrm{Si}$ ions in Mylar by a transmission technique, Nuclear Instruments and Methods in Physics Research Section B: Beam Interactions with Materials and Atoms 269 (24) (2011) 3046-3048. doi:10.1016/j.nimb.2011.04.069. URL http://dx.doi.org/10.1016/j.nimb.2011.04.069

[67] H. Ammi, C. A. Pineda-Vargas, S. Mammeri, M. Msimanga, S. Ourabah, A. Dib, Stopping power measurements of heavy ions $(3 ; Z 1 ; 14)$ in Mylar foil by time-of-flight spectrometry, Nuclear Instruments and Methods in Physics Research Section B: Beam Interactions with Materials and Atoms 269 (3) (2011) 386-391. doi:10.1016/j.nimb.2010.12.020.

URL http://dx.doi.org/10.1016/j.nimb.2010.12.020

[68] H. H. Lin, L. W. Li, E. Norbeck, Stopping powers of C, Al,
$\mathrm{Ni}, \mathrm{Cu}, \mathrm{In}, \mathrm{Sn}, \mathrm{Ag}$ and $\mathrm{Au}$ for $7 \mathrm{Li}$ ions of 1.0-4.7 MeV, Nuclear Instruments and Methods in Physics Research Section B: Beam Interactions with Materials and Atoms 17 (2) (1986) 9196. doi:10.1016/0168-583x(86)90070-4. URL http://dx.doi.org/10.1016/0168-583x (86)90070-4

[69] Y. Zhang, W. J. Weber, Electronic stopping of He, B, N, and $\mathrm{Al}$ in SiC, Applied Physics Letters 83 (8) (2003) 1665-1667. doi:10.1063/1.1604473. URL http://dx.doi.org/10.1063/1.1604473

[70] Y. Zhang, J. Jensen, G. Possnert, D. A. Grove, D. E. McCready, B. W. Arey, W. J. Weber, Electronic stopping forces of heavy ions in metal oxides, Nuclear Instruments and Methods in Physics Research Section B: Beam Interactions with Materials and Atoms 249 (1-2) (2006) 18-21. doi:10.1016/j.nimb.2006.03.013.

URL http://dx.doi.org/10.1016/j.nimb.2006.03.013

[71] Y. Zhang, J. Jensen, G. Possnert, D. A. Grove, I.-T. Bae, W. J. Weber, Stopping power measurements of He ions in $\mathrm{Si}$ and $\mathrm{SiC}$ by time-of-flight spectrometry, Nuclear Instruments and Methods in Physics Research Section B: Beam Interactions with Materials and Atoms 261 (1-2) (2007) 1180-1183. doi:10.1016/j.nimb.2007.04.276.

URL http://dx.doi.org/10.1016/j.nimb.2007.04.276

[72] A. J. M. Plompen, F. Munnik, J. Räisänen, U. Wätjen, Stopping powers of $200-3200 \mathrm{keV} 4 \mathrm{He}$ and $550-1550 \mathrm{keV} 1 \mathrm{H}$ ions in polyimide, Journal of Applied Physics 80 (6) (1996) 3147-3154. doi:10.1063/1.363277. URL http://dx.doi.org/10.1063/1.363277

[73] M. Msimanga, C. A. Pineda-Vargas, T. Hlatshwayo, C. M. Comrie, H. Ammi, M. Nkosi, Electronic stopping force of $12 \mathrm{C}$, $28 \mathrm{Si}$ and $63 \mathrm{Cu}$ ions in $\mathrm{HfO} 2$ and $\mathrm{SiO} 2$ dielectric films, Nuclear Instruments and Methods in Physics Research Section B: Beam Interactions with Materials and Atoms 322 (2014) 54-58. doi:10.1016/j.nimb.2014.01.003.

URL http://dx.doi.org/10.1016/j.nimb.2014.01.003

[74] Y. Zhang, High-precision measurement of electronic stopping powers for heavy ions using high-resolution time-of-flight spectrometry, Nuclear Instruments and Methods in Physics Research Section B: Beam Interactions with Materials and Atoms 196 (1-2) (2002) 1-15. doi:10.1016/s0168-583x(02)01246-6. URL http://dx.doi.org/10.1016/s0168-583x(02) 01246-6

[75] Y. Zhang, W. J. Weber, Role of energy partitioning on electronhole recombination, trapping, and detection in silicon detectors, Physical Review B 82 (7). doi:10.1103/physrevb.82.075202. URL http://dx.doi.org/10.1103/physrevb.82.075202

[76] G. F. Knoll, Radiation detection and measurement; 4th ed., Wiley, New York, NY, 2010.

[77] K. Jin, Y. Zhang, H. Xue, Z. Zhu, W. J. Weber, Ion distribution and electronic stopping power for $\mathrm{Au}$ ions in silicon carbide, Nuclear Instruments and Methods in Physics Research Section B: Beam Interactions with Materials and Atoms 307 (2013) 6570. doi:10.1016/j.nimb.2013.02.051. URL http://dx.doi.org/10.1016/j.nimb.2013.02.051

[78] H. J. Whitlow, Z. Y., Fundamental effects and non-linear si detector response, Nuclear Instruments and Methods in Physics Research Section B: Beam Interactions with Materials and Atoms 1-4 (2002) 375-378. doi:10.1016/S0168-583X(01)013027 . URL http://dx.doi.org/10.1016/S0168-583X (01) 01302-7

[79] K. F. Wallis, The Two-Piece Normal, Binormal, or Double Gaussian Distribution: Its Origin and Rediscoveries, Statistical Science 29 (1) (2014) 106-112. doi:10.1214/13-sts417. URL http://dx.doi.org/10.1214/13-sts 417

[80] H. Paul, Nuclear stopping power and its impact on the determination of electronic stopping power, AIP Conference Proceedings 1525 (1) (2013) 309-313. doi:10.1063/1.4802339. URL http://dx.doi.org/10.1063/1.4802339

[81] G. Was, Fundamentals of Radiation Materials Science, Springer, 2007.

[82] D. A. Thompson, W. D. Mackintosh, Stopping Cross Sections for $0.3-$ to $1.7-\mathrm{MeV}$ Helium Ions in Silicon and Silicon 
Dioxide, Journal of Applied Physics 42 (10) (1971) 3969-3976. doi:10.1063/1.1659712

URL http://dx.doi.org/10.1063/1.1659712

[83] C. Pascual-Izarra, M. Bianconi, G. Lulli, C. Summonte, Stopping power of $\mathrm{SiO} 2$ for $0.2-3.0 \mathrm{MeV}$ He ions, Nuclear Instruments and Methods in Physics Research Section B: Beam Interactions with Materials and Atoms 196 (3-4) (2002) 209-214. doi:10.1016/s0168-583x(02)01282-x.

URL http://dx.doi.org/10.1016/s0168-583x(02) 01282-x

[84] D. C. Santry, R. D. Werner, Energy loss of $4 \mathrm{He}$ ions in AI2O3 and $\mathrm{SiO} 2$, Nuclear Instruments and Methods in Physics Research Section B: Beam Interactions with Materials and Atoms 14 (2) (1986) 169-172. doi:10.1016/0168-583x(86)90040-6.

URL http://dx.doi.org/10.1016/0168-583x (86)90040-6

[85] B. M. U. Scherzer, P. Børgesen, M. A. Nicolet, J. W. Mayer, Determination of Stopping Cross Sections by Rutherford Backscattering, in: O. Meyer, G. Linker, F. Käppeler (Eds.), Ion Beam Surface Layer Analysis, Springer US, 1976, pp. 33-46. doi:10.1007/978-1-4615-8876-4_4.

URL http://dx.doi.org/10.1007/978-1-4615-8876-4_4

[86] H. Paul, Stopping Power for Light and Heavier Ions, https://www-nds.iaea.org/stopping/.

[87] W. N. Lennard, H. Xia, J. K. Kim, Revisiting the stopping powers of $\mathrm{Si}$ and $\mathrm{SiO} 2$ for $4 \mathrm{He}$ ions: $0.5-2.0 \mathrm{MeV}$, Nuclear Instruments and Methods in Physics Research Section B: Beam Interactions with Materials and Atoms 215 (3-4) (2004) 297307. doi:10.1016/j.nimb.2003.08.037.

URL http://dx.doi.org/10.1016/j.nimb.2003.08.037

[88] S. Markin, D. Primetzhofer, P. Bauer, Vanishing Electronic Energy Loss of Very Slow Light Ions in Insulators with Large Band Gaps, Physical Review Letters 103 (11). doi:10.1103/physrevlett.103.113201.

URL http://dx.doi.org/10.1103/physrevlett.103.113201

[89] K. Arstila, An experimental method for precise determination of electronic stopping powers for heavy ions, Nuclear Instruments and Methods in Physics Research Section B: Beam Interactions with Materials and Atoms 168 (4) (2000) 473-483. doi:10.1016/s0168-583x(00)00050-1.

URL http://dx.doi.org/10.1016/s0168-583x(00)00050-1 